Research Article

\title{
Measuring the Standardization Ability of Construction Enterprises from a Dual Perspective
}

\author{
Yikun Su, ${ }^{1}$ Huimin Wang $\mathbb{D}^{1}{ }^{1}$ Zhichao Zhou, ${ }^{1}$ Weisheng $\mathrm{Su}^{2}$ and Tingquan $\mathrm{He}^{3}$ \\ ${ }^{1}$ School of Civil Engineering, Northeast Forestry University, Harbin 150040, China \\ ${ }^{2}$ Guangxi New Development Transportation Group Co., Ltd., Nanning 530029, China \\ ${ }^{3}$ Guangxi Xinhengtong Expressway Co., Ltd., Nanning 530029, China \\ Correspondence should be addressed to Huimin Wang; wanghm@nefu.edu.cn
}

Received 2 August 2020; Revised 22 November 2020; Accepted 7 December 2020; Published 21 December 2020

Academic Editor: Changzhi Wu

Copyright (C) 2020 Yikun Su et al. This is an open access article distributed under the Creative Commons Attribution License, which permits unrestricted use, distribution, and reproduction in any medium, provided the original work is properly cited.

With the increase in large-scale engineering and construction projects and the enhancement of technical complexity, the ability to standardize has increasingly become one of the core elements of the overall competitiveness of construction enterprises. Previous studies have contributed to the relevant standardization ability literature. However, there remains a great deal of uncertainty concerning the standardization ability of construction enterprises (SACE). The measurable indicators still need to be further explored based on a comprehensive theory. This research aims to explore a model for evaluating the SACE and, explicitly, the status of standardization ability. The measurement index system for the SACE covers three dimensions and eight subcategories with 30 indicators which was established through a review of the literature and systematic analysis. A comprehensive measurement model for the SACE was designed from the dual perspectives of dominance and competitiveness. Finally, a case study was conducted to provide recommendations for policymakers to improve their standardization ability. The results indicate that the SACEs are inconsistent, and the vast majority of enterprises has relatively balanced standardization abilities. Furthermore, standardization ability is affected by the synergy of the three primary dimensions. Multiple linear regression was subsequently used to analyze the correlations among the three dimensions, which showed that there were obvious interaction effects and strong correlations among the three dimensions and indicated that the evaluation based on the three dimensions was reasonable. The findings are useful for the formulation of standardization policies and provide an evaluation and testing model for decision makers to improve their standardization ability.

\section{Introduction}

The comprehensive development level of construction enterprises has a crucial effect on all aspects of economic development [1] as well as the environment [2,3]. Realistic indicators commonly used in statistical data, such as profit, output value, and quality, cannot objectively and comprehensively reflect the productive and operational capacity of construction enterprises [4], especially in construction enterprises of different scales and professional degrees. In recent years, the issue of enterprise standardization has attracted increased attention [5]. With the increase in large-scale engineering and construction projects and the improvement of technical complexity, the ability to standardize, which is a significant indicator reflecting the overall production capacity and level of enterprises, has increasingly become one of the core elements of the overall competitiveness of construction enterprises [6]. All aspects of strategic benefits, such as time, cost, and efficiency, are obtained by enterprises via standardization processes [7] to boost their continuous development [8] and promote a gradual trend towards the standardization and rationalization of enterprise production modes [5, 9]. In this study, the standardization ability of construction enterprises (SACE) was described as the capacities and levels of the production and operation entities engaged in various construction activities to complete various standardization tasks, including the formulation [5], issuance, and implementation of standards within the scope of the production and operation activities $[5,10,11]$. 
In actual practice, it is a measure of the degree to which the knowledge and skills of the enterprise are created and applied so that the best production and operation processes and all aspects of economic benefits can be obtained by the enterprise [12]. Previous studies have focused on promoting the development of construction enterprises by means of improving quality and safety management $[5,13]$, technical standardization $[12,14,15]$, etc.; however, several problems have also hindered this development, including but not limited to standardization processes $[16,17]$. The ability to standardize was too low to be comprehensively evaluated in terms of these aspects. Hence, standardization ability is the key factor in enhancing the overall development level of enterprises, instead of improving a single ability. In our research, we find that the SACE results from the interaction of multiple subsystems, such as the status of standards adoption by enterprises, the process for standardizing activities, and the beneficial outputs. Our research provides a comprehensive evaluation of various factors concerned. There is no unified procedural specification for the standardization behavior of construction enterprises [18], which has resulted in wide variation in the standardization ability of different construction enterprises. Measuring the SACE is highly important in improving construction enterprises' standardization ability, enhancing their competitiveness, and improving the degree of equilibrium in the standardization level of the whole industry.

The concept of standardization ability is comprehensive, encompassing a series of standardization activities, such as the formulation of standards (the manner in which standards are developed has an profound effect on enterprises [5]), the implementation process (including planning, measuring, designing, constructing, inspecting, and accepting [11]), and the assessment of the effect of standardization activities (which represents quality, environmental, safety, and efficiency effects $[9,19,20])$. SACE has become a crucial indicator in evaluating the comprehensive development level of construction enterprises. Nevertheless, the relevant literature has mainly focused on the interpretation of definitions of standardization and the ability to standardize a single element, such as management and technology. There is neither a widely accepted definition of standardization nor a system of scientific evaluation indicators. Additionally, the requirements of comprehensive evaluation theory have been neglected in the indicator systems for the standardization ability that have been constructed. In contrast, the selection of evaluation methods, in terms of the method itself (combination of subjective and objective methods, combination of objective methods, etc.), has mostly been based on comprehensive evaluation theory and has stressed the identification of index weights [21]. However, the practical problems identified by the guiding principle have been ignored.

To solve the above problems, a systematic set of indicators to evaluate the SACE was designed with the objective of measuring the SACE according to the principles of comprehensive evaluation theory. This set was composed of indicators for the quality, process, and benefit dimensions and objectively and comprehensively reflected the multidimensional characteristics of the SACE. A comprehensive measurement model for the SACE was established from the dual perspective of dominance and competitiveness based on actual needs; this model can be used not only to measure the SACE but also to reflect the differences in the degree of standardization ability among construction enterprises. Finally, the measurement model was utilized to evaluate the SACE through a case study, and suggestions for decision makers and relevant personnel were provided to help advance the continuous development of enterprises.

This paper is organized into six sections. A literature review is presented in the second section, which primarily elaborates the previous research results relating to the main problems addressed by this study. The methodology is addressed in the third section, in which the identification of the elements of the indicator system for evaluating the SACE, the determination of the indicator system, and the establishment of the comprehensive measurement model based on the dual perspective of dominance and competitiveness are described in detail. The comprehensive measurement model is verified in a case application in the fourth section, which guides the decision maker through the implementation of the evaluation model. The evaluation results and discussion, as well as the conclusion, are presented in the fifth and sixth sections, respectively.

\section{Literature Review}

2.1. Standardization Ability Evaluation. Standardization is a set of dynamic processes $[6,22]$ that transform complex and disordered phenomena into simple and orderly processes [23] and that play a normative role in the market structure and the competition order [24]. Moreover, the standardization process is characterized by continuous development, complexity, and systematicness [22, 25]. Techatassanasoontorn and Suo [26] found that the process of standardization evolution not only reflects complex characteristics but also shows that the trend in most of its dynamic development processes follows an S-shaped curve. In the research on the indicators used to measure the standardization ability, Lee and Oh [27] analyzed the differences in the process of standardization evolution and the factors that influence those differences and took the institutionalization and promotion of standards as the basis for evaluating the standardization ability. Zeng et al. [10] assumed that the standardization ability is reflected in technology selection and the formulation and promotion of standards. Some researchers also represented the standardization ability with technical ability [28], project quality standards [29], etc. Moreover, the research and development (R\&D) of standards, the adjustment of standards in the process of conducting standardization activities, and the dynamic evolution of standards could be used as a basis for measuring the standardization ability [30]. Saugstrup and Henten [31] performed a study in which the effect of standardization was assessed in terms of network effects and strategies and pointed out that the product stakeholders involved in the standardization 
process participated in the standardization process in various ways.

\subsection{Evaluation of the Standardization Ability of Construction} Enterprises. Construction enterprises have paid less attention to technical innovation and technical standards than to traditional management modes [32-34]. Recently, awareness of the importance of engineering construction standards in meeting goals such as raising work efficiency and reducing negative environmental impact and risk $[9,19,20]$ has gradually increased among enterprises, which has led decision makers to attach importance to strategic benefits brought about by standardization: reductions in time and cost and the avoidance of mistakes [7].

Enterprise standardization is closely correlated with its development $[14,15,35-37]$ and plays a key role in improving competitiveness $[6,22]$. The process of standardization involves many resources related to technology, information, and human resources $[22,26]$. According to Jiang et al. [37], standardization plays a vital role in the development of enterprises, which coincides with the views of Jiang et al. [38]: standardization led to a chain reaction in development; moreover, a synergistic effect exists between development and standardization [37]. Participation in the standardization activities has a positive impact on the enterprise performance [12]. On the basis of examining the factors influencing the effect of standardization on the enterprise performance, Paik et al. [39] came to the same conclusion that enterprise standardization has a direct positive effect on the enterprise performance. Standardization can promote the development of enterprises [8], which can push enterprises towards standardization [5].

2.2.1. Research on the Indicators for the Evaluation of the Standardization Ability of Construction Enterprises. Measurement indices for the SACE have been discussed in the existing literature. To measure the state of the SACE, Wei [40] used the standardized foundations and the construction level, degree of implementation, and economic benefits to measure the standardization status of construction enterprises, while Yang et al. [41] underlined the advantages found in the market and technology. In addition, timely and accurate information obtained in the construction process could provide feedback on the quality of a standard itself [42] and could speed up the project progress by improving the quality of the standard, which could reflect the standardization ability of the enterprise [43]. Regarding comprehensive evaluation theory, research on the functional mechanism underlying the effect of standardization on the competitive advantage of enterprises was investigated by Jiang [44]. An assessment of the enterprise's strategic ability to standardize was conducted in order to understand the enterprise's choice of standardization strategy from the perspective of the implementation of the strategy, a focus on customers and the amelioration of internal management problems. Previous scholarly research on the system of indicators for the evaluation of the standardization ability of enterprises has mainly concentrated on the construction of the index system and its strategic suggestions on the basis of empirical analysis.

A portion of previous studies regarding the SACE have made progress in the aspects of technology, safety, and quality $[13-15,36]$. In a single case study, for instance, Fang et al. [25] proposed a standardized management mode, and the importance of standardization was determined through interviews. In addition, three core elements needed by enterprises, including strategic planning, $\mathrm{R} \& \mathrm{D}$, and innovation, were emphasized. Similarly, Liu and Tian [13] created an index system for estimating comprehensive security using qualitative descriptions and quantitative data, including human factors, material elements, environmental considerations, and management factors. In the next stage, to address safety problems, a cloud-based early-warning mechanism was constructed based on extended cloud theory and distributed computing methods to judge the overall state of building safety in the construction process. To improve the mechanism behind safety standardization, Huang et al. [45] extracted and purified the primary elements of safety standardization and analyzed the relationship and interactions between them. Then, enterprise safety standardization was explored by using a five-party mechanism model with synthetic and systematic methods. As a result, measures to optimize the implementation process of safety standardization activities were given.

\subsubsection{Research on the Methods for Evaluating the Stan-} dardization Ability of Construction Enterprises. Certain scholars have made efforts to evaluate the SACE, and many proposed strategies to augment standardization ability and have made relevant contributions to the promotion of the standardization ability. Considering the influence of technology and information on standardization, Zhang et al. [46] adopted a Cobb-Douglas function to verify enterprise standardization ability and found that standardization has an obvious role in promoting the economic benefits of enterprises. Furthermore, a reference for enterprises on the formulation of standardization strategies was provided as a result of the investigation on the relationship between standardization and economic benefits. Zeng and Wang [47], analogously, employed correlation analysis and descriptive statistics to make a thorough inquiry into the relevant variables. Subsequently, a negative binomial regression was applied to verify the ability of enterprises to standardize their technologies. Finally, the intermediary role of technological standardization in competition among enterprises was also discussed. Previous studies have barely discussed standardization strategies. Differences in the technical levels between enterprises were reflected by their technical standardization levels, which determined the competitive position of enterprises and affected their economic and technological development. Accordingly, the standardization ability and performance of enterprises could be improved by strengthening the management of their technological standardization $[6,39]$. Strengthening the management quality of construction enterprises could also 
be regarded as an effective path to improving standardization ability [4]. As mentioned in the research of Newaz et al. [48], the process of improving the standardization ability should be considered from the point of view of safety management, which was the conclusion drawn from the diagnosis of the building safety environment using a multifactor model. Then, a structural equation model was proposed to explore safety behavior problems, indicating that the standardization of safety management is also a part of enterprise standardization ability. As a result, suggestions for improving the standardization ability of enterprises were given [49]. Moreover, the research conducted by Jahren and Johnston [50], in which the initiative to develop and revise standards during the standardization process was found to be a way of improving standardization ability. The best benefits of standardization efforts are a result of unifying technology and management and of standardizing production and operation order [45].

As pointed out above, the research on evaluation methods has been mainly focused on the identification methods of measurement index weights, including subjective weighting methods [51], objective weighting methods [52], and subjective and objective comprehensive weighting methods [53]. Luan and Xie [54] determined the weights of indicators according to fuzzy comprehensive evaluation theory and analytical hierarchy process, and then the safety production standardization of enterprises was evaluated. Jiang et al. [23] studied the evaluation method of enterprise's technology standardization ability by using grey relative correlation, absolute correlation, and comprehensive correlation and considered that only under the condition of mutual adaptation can technology standardization and technology development promote each other. Wang and Gao [55] utilized the fuzzy integrated evaluation method to estimate the safety quality standardization. However, Jiang et al. [6] developed technology standardization and innovation model based on the eutectic solidification theory to study the technology standardization ability of enterprises, but did not compare the differences between standards (formal standards and factual standards). Newaz et al. [49] evaluated the safety standardization of enterprises using the structural equation model. The identification of index weights is mostly from the method itself. Considering the practical problems, this study proposed a dual perspective of the evaluation method of standardization ability.

2.3. Review of the Existing Studies. Progress has been made in the research of standardization indicator systems, evaluation methods, and implementation strategies for construction enterprises. However, the ability to standardize a single element has been the primary focus. Standardization ability is an abstract and multidimensional construct that has not yet been formed into an integrated system or framework, and the identification of indicator weight lacks guidance. The production and operation abilities and levels of construction enterprises are not confined to benefiting the economic, quality, safety, and other aspects of enterprise outcomes [4]. In this paper, a multidimensional and multilayer indicator system for evaluating the SACE was structured in accordance with comprehensive evaluation theory and comprised the three primary dimensions of quality, process, and benefit, as well as eight subcategories. Considering the practical problems involved in evaluation, a comprehensive measurement model based on dominance and competitiveness was constructed to measure the SACE.

\section{Research Methods}

This study aims to build an index system for measuring the SACE and a comprehensive measurement model based on actual evaluation needs. The research process was divided into three stages: (1) on the basis of literature collection and collation, this paper analyzed the characteristics of standardization ability, identified the elements of standardization ability, and selected the indicators of standardization ability. Combined with the relevant theory of comprehensive evaluation and existing research results, the index system for evaluating the SACE was determined. (2) In this stage, according to the actual needs of evaluation, we developed an evaluation model to comprehensively measure the SACE from a dual perspective. (3) Case studies are conducted to guide the decision makers to implement the evaluation model to evaluate and test the SACE. The overall research framework is shown in Figure 1.

\subsection{Construction of the Index System for the Standardization Ability of Construction Enterprises}

3.1.1. Elements of the Standardization Ability of Construction Enterprises. The formation of the SACE should be a complete process from beginning to end. In this study, the whole process of standardization in construction enterprises comprised the adoption of standards $[5,10,40,41,56]$, the process of standardization $[11,17,40,57,58]$, and the receipt of benefit $[10,40,56-59]$. The main characteristics of the standardization ability of enterprises are as follows: first, the standardization activities of construction enterprises are the groundwork needed to ensure the quality of production and operation activities [19]. The engineering construction standards adopted by the enterprise are the foundation for technical activities in the construction process [60]. The quality of the living environments constructed and the transformation and upgrading of enterprises are affected by the quality of the standards [5], which also play an indispensable role in project management [19]. The formulation and revision of standards, which includes the process of standardizing and disseminating the optimal plans for production and operation activities and safeguarding the interests of enterprises [5], is of vital importance to enterprises [5, 19]. Second, standardization in construction enterprises is a longterm process, including standardizing daily work, practically applying standards to construction activities, and implementing the construction enterprises' standards. Standardization activities comprise the whole system in which different professional organizational units logically complete a series of processes. The key technical activities and achievements of construction enterprises are closely bound up with the 


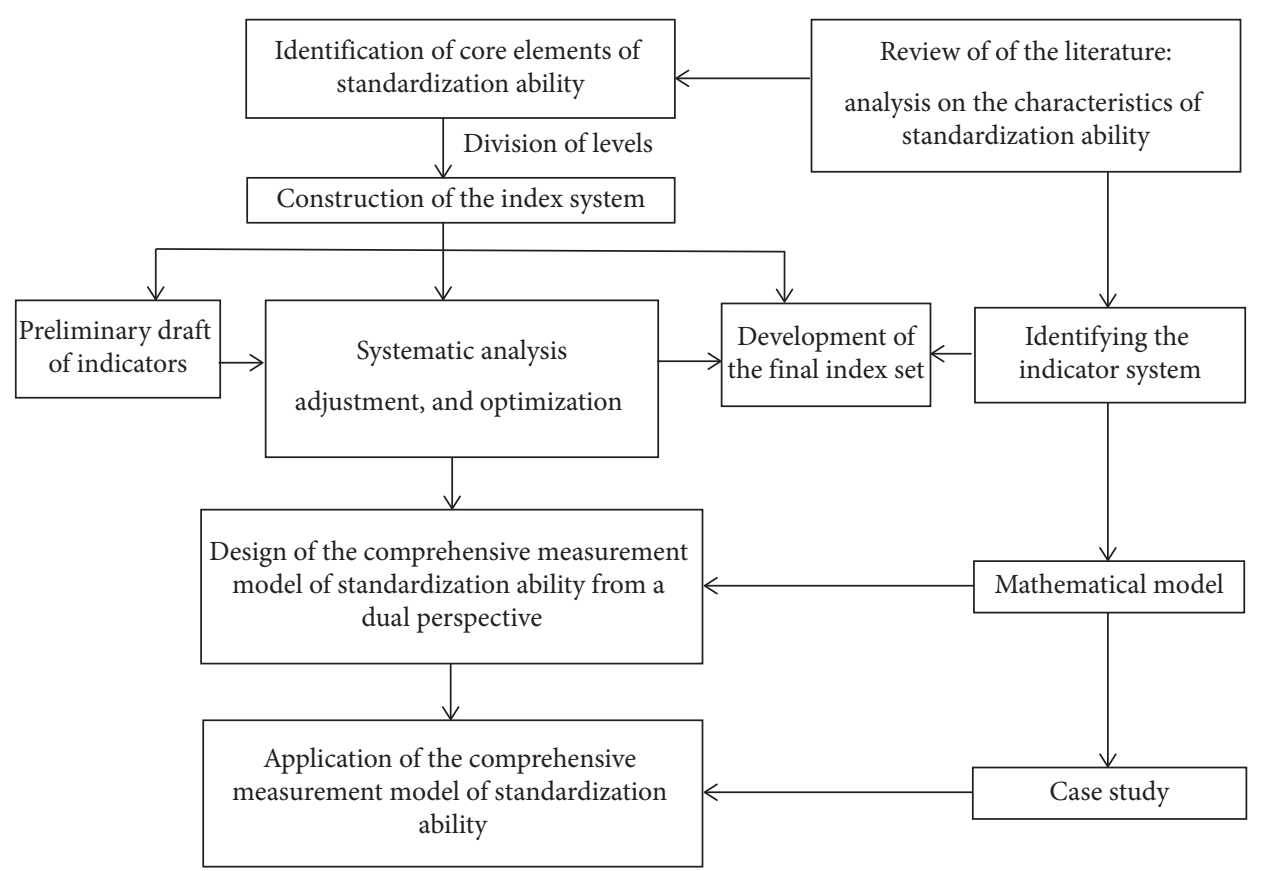

Figure 1: Overall research framework for this study.

implementation of engineering construction standards, which originate from the determination and implementation of the most effective management practices and workflows [17]. Third, the effect of standardization activities reflects the quality, safety, environmental, and other aspects of the construction project after the practical implementation of the standard, i.e., the effect generated by the operational status of each link had feedback effects in the benefits generated. The capacity to generate benefits not only depends on the adoption of standards by the construction enterprises [61] and the ability to practice standardization activities (participation in standardization activities has a positive effect on the enterprise performance [12]) but also determines the operational status of the enterprise itself. The SACE was composed of three elements: the status of standards adoption by construction enterprises, the process of practicing the standardization activities, and the resulting benefits, which interacted with each other around the goal, as shown in Figure 2.

The results of the SACE indicator decision were influenced by the elements. Based on the connotation and characteristics of the SACE, the measurement indicators for the standardization ability were distributed across the above three dimensions, which were equally important in the evaluations of standardization ability. Therefore, three primary dimensions-quality, process, and benefits-were chosen to measure the SACE.

3.1.2. Indicator System for the Evaluation of the Standardization Ability of Construction Enterprises

(1) The Principle behind the Selection of Standardization Ability Indicators. This paper uses the evaluation of the
SACE as a jumping-off point. Based on theoretical analyses $[62,63]$ and existing research results, the construction of an index system to evaluate the SACE against the current social backdrop should follow the following principles:

First, the evaluation method should be comprehensive and systematic. Therefore, our goal is to extract the "main" indicators reflecting the SACE to the greatest extent possible and to measure the standardization ability from multiple angles.

Second, the principle of goal orientation implies that the construction of an index system for standardization ability should be based on certain guidance so that each indicator of standardization ability is directed towards the chosen goal.

Third, the principle of correlation means that there should be an obvious correlation between the selected indicators and the SACE.

Fourth, the principle of comparability requires that different construction enterprises should be comparable across each standardization ability indicator.

Fifth, the principle of operability means that data for each standardization ability indicator are available and that the indicator type has no ambiguity so that the indicator can be used in the evaluation of standardization ability.

(2) Identifying the Indicator System for the Evaluation of the Standardization Ability of Construction Enterprises. The initial set of standardization ability indicators was subsequently determined by summarizing the research findings on standardization (Elghamrawy and Boukamp [42]; Techatassanasoontorn and Suo [26]; Chen [64]), combining 


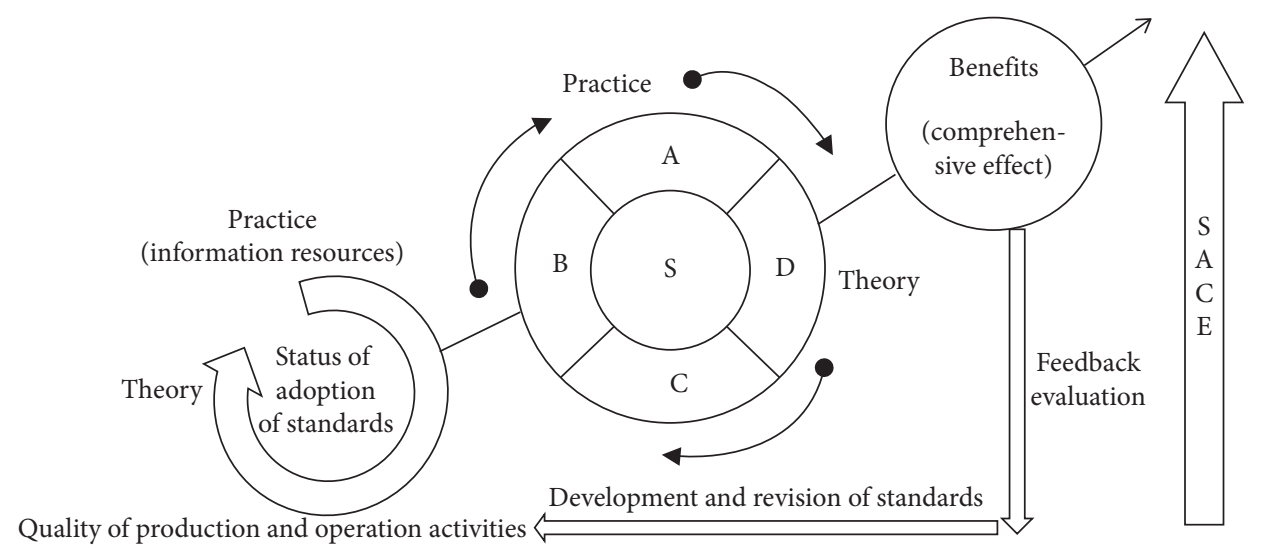

FIgURE 2: The elements of the SACE. S, behavioral system, the process for practicing standardization; A, status of daily work standardization; $\mathrm{B}$, implementation progress; C, practical application status; D, feedback effect; SACE, standardization ability of construction enterprises.

the relevant literature on enterprise standardization (Guo et al. [65]; Wei [66]; Wei [40]), referring to the standard system for engineering construction (Zhang [56]; Dong [67]; Jia [57]; Wu [59]; Liu [58]; Sun [68]), and integrating the technical standardization indicator systems of industries and enterprises (Wang et al. [69]; Zeng et al. [10]; Yang et al. [41]).

The initial indicator set obtained above was filtered and categorized in a process of classifying, conducting interviews, adjusting, optimizing, and conducting mathematical analyses [60] and was divided into eight subcategories to create the division of three index levels shown in Figure 3. The SACE is measured, in turn, at different levels, the target layer, the primary dimensions, and the subcategories, which avoids the limitations of a single-level evaluation. The corresponding primary dimension was determined for each subcategory, which revealed the difference and the consistency between the subcategory and the primary dimension. In addition, the target level was determined by the primary dimensions. Different dimensions have different effects on the SACE. The specific process for filtering the indicators for the standardization ability of construction enterprises has been studied in [60].

With the measurement of the SACE as the goal and in light of the existing research results and principles of index selection discussed above, the indicator system was constructed to have three primary dimensions (quality, process, and benefits), eight subcategories, and thirty specific indicators corresponding to each subcategory. This resulted in the final terminal indicators used to evaluate the SACE as follows.

Primary dimension $B_{1}$ (quality) was composed of two subcategories: the normalization of the standards adopted by construction enterprise $c_{1}$ and the scientific quality of the standards adopted by construction enterprise $c_{2}$. The indicators in subcategory $c_{1}$ are the structural rationality of the engineering construction standards adopted by enterprise $c_{11}$, the practicality of the technical methods required by the engineering construction standards $c_{12}$, and the cycle and frequency of standard updating $c_{13}$. Indicators included in subcategory $c_{2}$ are the operability of the engineering construction standards $c_{21}$, the internationalization level of the adopted engineering construction standards $c_{22}$, and the proportion of the business covered by the adopted standards $c_{23}$.

Three subcategories were subordinate to primary dimension $B_{2}$ (process), namely, the status of daily work standardization in enterprise $c_{3}$, the status of the practical application of the standards in construction activities $c_{4}$, and progress in the implementation of the construction enterprise's standards $c_{5}$. The indicators belonging to subcategory $c_{3}$ are as follows: the enterprise's participation rate in publicity for and implementation of engineering construction standards $c_{31}$, the standardized staffing of enterprises $c_{32}$, the initiative of the construction enterprise in formulating and revising standards $c_{33}$, the enterprise's participation in standardization activities in China and in other countries $c_{34}$, and whether the enterprise has incorporated the standard into the management system $c_{35}$. The indicators composing subcategory $c_{4}$ are as follows: the degree to which engineering construction standards are mastered by technical personnel $c_{41}$, the proportion of construction enterprises implementing construction standards $c_{42}$, the frequency of controllable accidents in construction $c_{43}$, and the regulation of construction behaviors by the enterprise $c_{44}$. Indicators including the proportion of construction that meets standards $c_{51}$, the percentage of standards adopted by enterprises $c_{52}$, progress towards the full improvement of the standards' system $c_{53}$, and the completion rate for upgrades of related supporting facilities $c_{54}$ are all involved in subcategory $c_{5}$.

Primary dimension $B_{3}$ (benefits) was composed of social benefits $c_{6}$, economic benefits $c_{7}$, and technical benefits $c_{8}$. The social benefits subcategory $c_{6}$ consists of the following indicators: the optimization and enhancement of construction management $c_{61}$, the influence on the ecological equilibrium $c_{62}$, and the ability to guide and regulate the construction market $c_{63}$. Indicators contained in the subcategory of economic benefits $c_{7}$ are the rate of increase in the profits earned $c_{71}$, the effect on the promotion of project development $c_{72}$, the rate of improvement in production efficiency $c_{73}$, and the rate at which standards are 


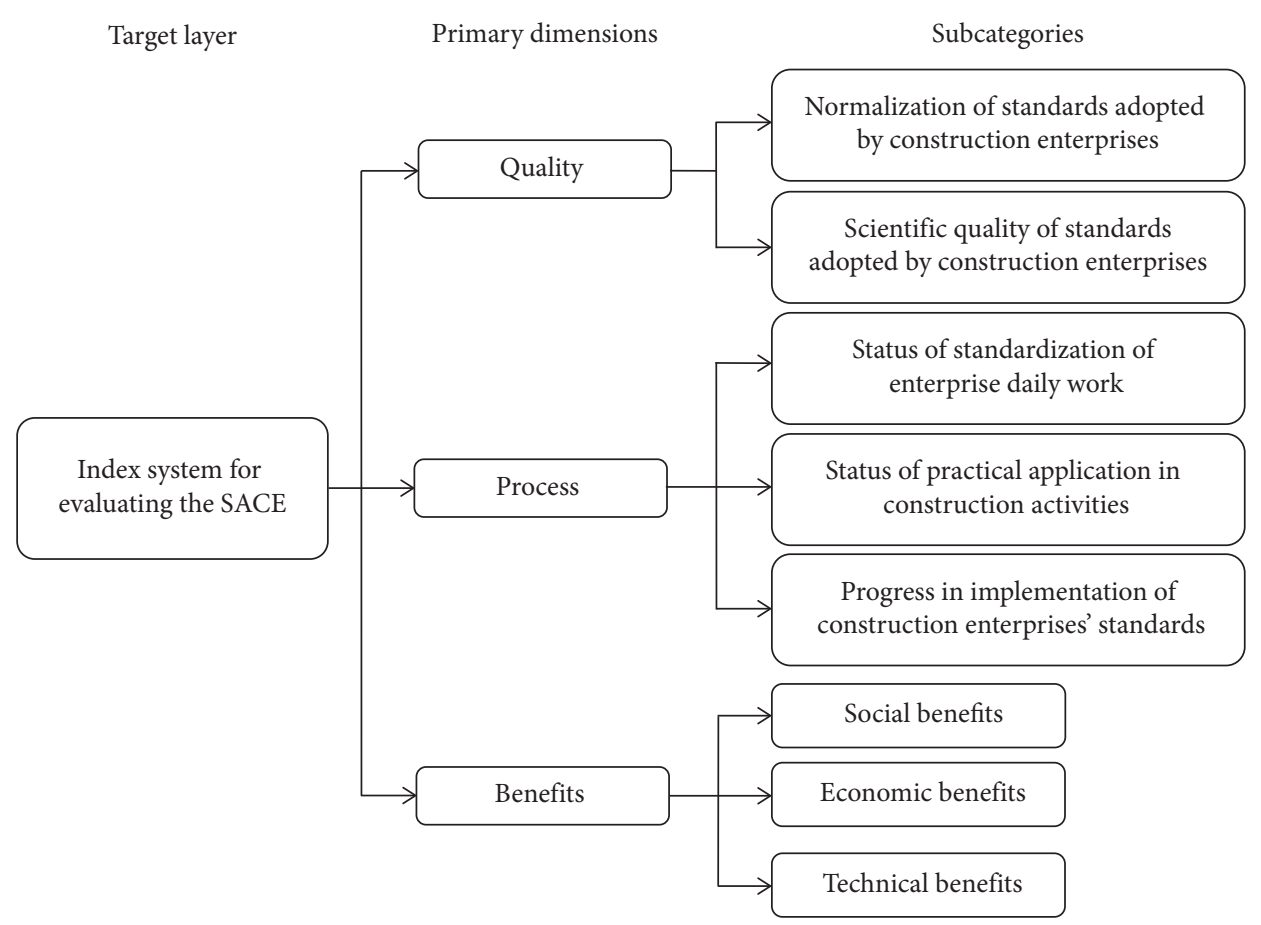

FIGURE 3: Framework for the multidimensional and multilayer SACE evaluation system.

implemented to make use of enterprise resources $c_{74}$. The subcategory of technical benefits $c_{8}$ is composed of the following indicators: the catalytic effect on technological $\mathrm{R} \& \mathrm{D}$ and innovation $c_{81}$, dissemination and application of scientific and technological achievements $c_{82}$, the degree to which the transformation and upgrading of the enterprise has advanced $c_{83}$, and the degree to which the level of professional cooperation is strengthened $c_{84}$.

\subsection{Measurement Model for the Standardization Ability of Construction Enterprises from a Dual Perspective}

\subsubsection{Measurement Principle for the Standardization Ability} of Construction Enterprises. The comprehensive measurement of the SACE was based on multiple concept levels and contained a multidimensional variable structure. Concerning the constructed indicator system (see Figure 3), the evaluation was conducted on different levels and multiple dimensions to ensure the reliability and accuracy of the evaluation results [70]. The comprehensive measurement was carried out from the perspectives of demand-driven capacity and competitive differentiation (dual perspective). The measurement principle of the SACE is displayed in Figure 4.

3.2.2. Method of Measuring the Standardization Ability of Construction Enterprises Based on the G1 Weighting Method with Dominance and a Transformation Function. It is noted above that the overall production and operation level of construction enterprises was not high enough to be comprehensively and objectively reflected by the empirical indicators commonly utilized in statistical data [4]. In addition, given the current development needs of the society and the environment, it is necessary to accurately grasp the demand-driven production and operation capacity of construction enterprises [1-3].

Subject to goal orientation, this paper is based on the G1 weighting method and relies on the subjective judgment of experts in the standardization field to understand the current environment and choose appropriate indicators. This method meets the needs of the SACE evaluation method. In view of the G1 method using dominance and a transformation function, a new weighting method was outlined, which not only required that the identification of the relative importance of adjacent indicators not only leans on the subjective judgment of the rational experience of experts but also makes the measurement more objective. The demanddriven level of the standardization ability of construction enterprises is reflected in the evaluation results.

The basic idea behind this new weighting method is to define the order relation of each indicator according to the importance of each indicator, and the dominance for each evaluation indicator was obtained. Then, a transformation function based on the dominance was introduced to calculate the ratio of importance between adjacent indicators. Therefore, the weight coefficient on each indicator was determined by the G1 weighting method.

(1) Determining the Weights for the Indicators of the Standardization Ability of Construction Enterprises.

Step 1: identifying the order of importance of the evaluation indicators. The value of the evaluation indicator $c_{g}$ for the focal construction enterprise $d_{l}(l=$ 


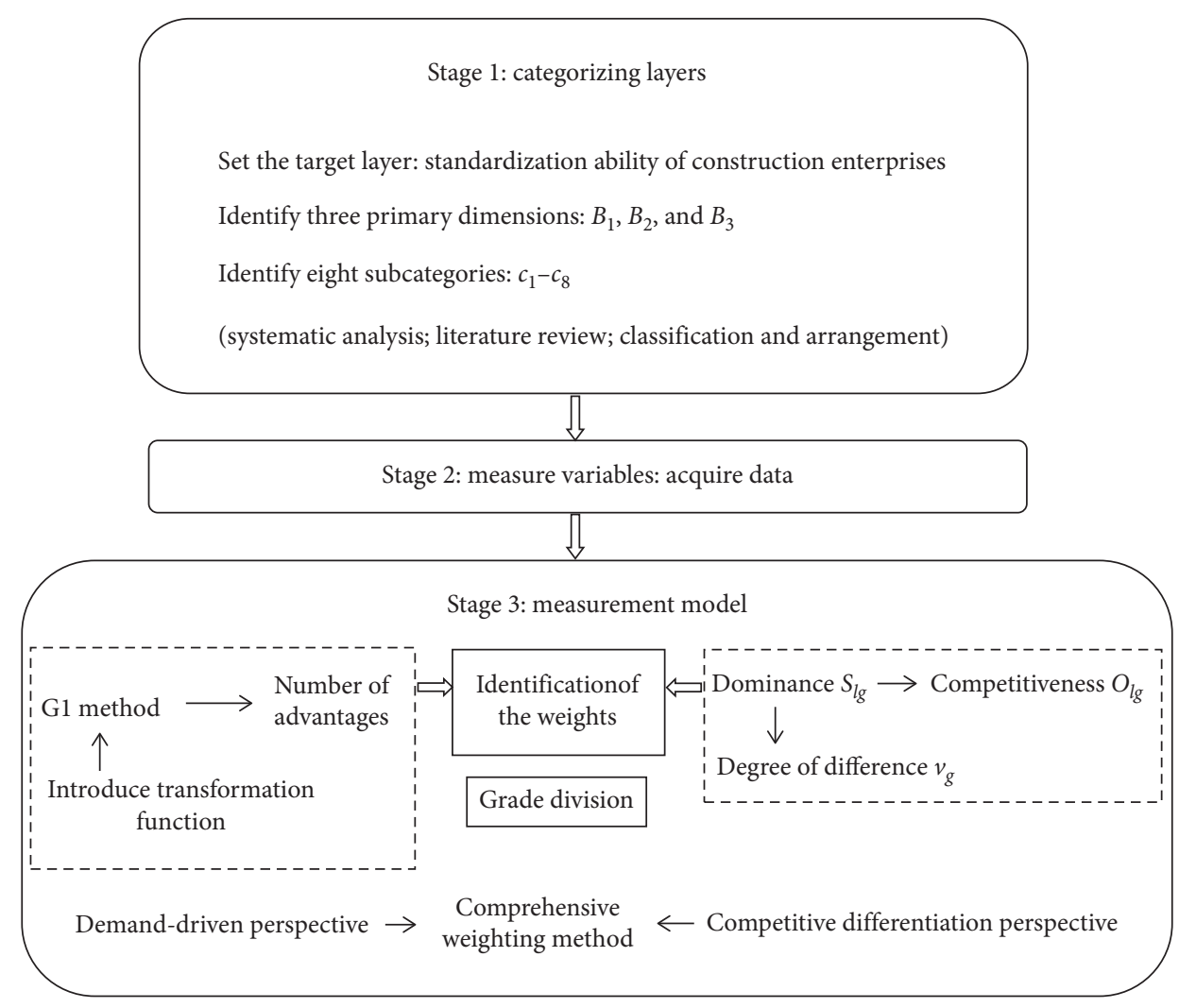

FIgURE 4: Three-stage multilevel measurement principle.

$1,2, \ldots, 20)$ was denoted as $c_{l g}$. Experts working in engineering construction standards and professionals doing work related to the establishment of standards in institutions of higher learning were consulted in this process. These experts ranked the corresponding indicators for each level of the indicator system and created the hierarchy. The ranked results are recorded as

$$
c_{1}>c_{2}>\cdots>c_{p}
$$

Note: $c_{g}(g=1,2, \ldots, p)$ represents the $g$-th evaluation indicator for standardization ability after ranking, i.e., ranked at the $g$-th position, indicating that indicator $c_{g}$ is more important than $p-g$ indicators. The dominance of indicator $c_{g}(g=1,2, \ldots, p-1)$ is defined as

$$
t_{g}=p-g
$$

The higher the ranking of the evaluation indicators is, the more important the indicators are than other indicators and the more attention they receive from construction enterprises.

Step 2: identifying the ratio of importance between adjacent indicators. After the importance ranking of the evaluation indicators conducted above, the ratio of importance between adjacent indicators also needs to be determined in order to conduct the G1 weighting method. The difference between the final computed indicator weight values should not be too large, and the weight values should be rational [71], i.e., the weight ratio between any two adjacent evaluation indicators should be greater than or equal to $1: c_{h-1} / c_{h} \geq 1$. The least important evaluation indicator $c_{p}$ was given a weight of 1 , and the weight ratio of the most important indicator $c_{1}$ to the least important indicator $c_{p}$ should not be too large.

Function $g(c)=(1+c)^{m},(m>0)$, was introduced. It is evident that as the value of $m$ increases, so does the value of function $g(c)$. Consequently, $g(c)$ is an increasing function, and when $c$ takes on the special value $0(c=0), g(c) \equiv 1$. The idea used in this paper is that the relevant indicators were weighted following the traditional G1 weighting method (the importance of the indicator is indicated by the value of the weight coefficient: the greater the weight, the more important the indicator). This is consistent with the monotonic characteristics of function $g(c)$. Hence, the function $g(c)$ can be viewed as a transformation function that calculates the ratio of the importance of indicators. The indicator weighting method that uses the dominance and the transformation function is given in detail.

The importance ratio between indicators $c_{h}$ and $c_{h-1}$ is called $R_{h}=u_{h-1} / u_{h}$, and $R_{h}(h=2,3, \ldots, p)$ is the variable to be solved for. The aforementioned function $g(c)$ is the transformation function, and the relative importance between the two indicators $c_{h}$ and $c_{h-1}$ was 
determined by taking the dominance $\left(t_{g}=p-g\right)$ into consideration. $R_{h}$ was calculated by

$$
R_{h}=[(p-g)+1]^{m},
$$

where $g=1,2, \ldots, p-1, h=2,3, \ldots, p$, the dominance of the least important indicator $c_{p}$ is $t_{p}=0$, and $g\left(c_{p}\right)=1$ correspondingly. The following relationship between $R_{h}$ and $u_{p}$ adheres to the G1 weighting method:

$$
u_{p}=\left(1+\sum_{h=2}^{p} \prod_{i=h}^{p} R_{i}\right)^{-1}
$$

Symbolically, the relationship between $u_{h-1}$ and $u_{h}$ can be depicted as follows:

$$
u_{h-1}=R_{h} u_{h}, \quad h=2,3, \ldots, p .
$$

By the aid of the calculated importance ratio $R_{h}$ between adjacent standardization ability indicators, the weight of each indicator was determined through equation (6), derived as follows:

$$
u_{1}=u_{p} \prod_{h=2}^{p} R_{h} \text {. }
$$

Step 3: solving for the weights of the standardized ability evaluation indicators. Under the condition that the value of $m$ is defined, let $F=\prod_{h=2}^{p} R_{h}$, where $F$ is a constant value, and

$$
F=\prod_{h=2}^{p} R_{h}=\frac{u_{1}}{u_{p}}=p^{m}(p-1)^{m}, \ldots, 3^{m} 2^{m} .
$$

The discrepancy in indicator weights is related to the value of $F$, i.e., the degree of the discrepancy between weights is determined by the value of $F$, and the weight difference increases with an increase in the value of $F$. The maximum value of $F$ is defined as follows: using indicator $c_{1}$ and indicator $c_{p}$ as examples, $F=u_{1} / u_{p}=t_{1}+1 ; t_{1}$ represents the dominance of indicator $c_{1}$, illustrating that indicator $c_{1}$ is more important than the $t_{1}$ indicators compared with it; the indicator with the lowest importance is denoted $c_{p}$, and its value is 1 . The value of $F$ can also be given subjectively based on the practical problems of evaluation. The weight coefficient conditional on the value of $F$ being defined is

$$
\begin{aligned}
& F=t_{1}+1, \\
& \text { s.t. }\left\{\begin{array}{l}
F=p^{m}(p-1)^{m} \ldots 3^{m} 2^{m}, \\
{[(p-g)+1]^{m}>1, \quad g=1,2, \ldots, p-1 .}
\end{array}\right.
\end{aligned}
$$

The parameter $m$ is defined in terms of equation (8), and then the weight coefficient is calculated with equations (3)-(5).
(2) Measurement Value of the Standardization Ability of Construction Enterprises Based on Dominance and the Transformation Function.

The weight of each indicator that was determined via the G1 weighting method in light of the dominance and transformation function was set as $u_{c_{n}, 1}, u_{c_{n}, 2}, \ldots, u_{c_{n}, k_{n}}$, and the measurement results for the SACE from the perspective of demand-driven capacity were incorporated into the identification of the indicator weights:

$$
X_{l}=\sum_{n=1}^{q} u_{c_{n}} \sum_{g=1}^{k_{n}} u_{c_{n}, g} c_{l g}
$$

where $X_{l}$ is the estimated standardization ability of the construction enterprise $d_{l}$ driven by demand and $u_{c_{n}}$ is the weight of the criterion layer, $n=1,2, \ldots, q$. The computational process is that given above. $k_{n}$ represents the number of indicators for standardization ability contained in criteria layer $c_{n}$, which satisfies equation $k_{1}+k_{2}+\cdots+k_{q}=p$.

The measurement method for the demand-driven capacity perspective was to assess the SACE and understand the enterprises' overall production and operation level. The demand-driven SACE not only has a high measurement value but also exhibits balanced development in each standardization ability indicator, which gradually reinforces enterprise competitiveness.

\subsubsection{Measurement Method of the Standardization Ability} of Construction Enterprises from the Perspective of Competitiveness. In addition to ensuring that the construction enterprise has a high overall evaluation value, in an ideal situation, its production and management capacities and levels should also reflect strong competitiveness and balanced development in each standardized ability indicator. The objective weighting method for the perspective of competitiveness was selected to evaluate the degree of equilibrium in the development of the construction enterprises, which not only clearly demonstrates the overall differences between the assessed construction enterprises but also explicitly reveals the relative dominance of different construction enterprises in each evaluation category (local differences). It is currently difficult to measure the competitiveness of enterprises by measuring the comprehensive development level of the construction enterprises. This paper, therefore, proposes an objective weighting method from the perspective of competitive differences.

(1) The Competitiveness of the Evaluated Construction Enterprises Should Be Reflected in Each Indicator.

The dominance of the evaluation indicator $c_{g}$ for the evaluated construction enterprise $d_{l}$ across all the evaluated construction enterprises was set as $s_{l g}$, and the ideal point method was used to describe the competitiveness of the evaluated construction enterprises in each evaluation category: 


$$
\begin{aligned}
& c_{g}^{+}=\max _{l}\left\{c_{\mathrm{lg}}\right\}, \\
& c_{g}^{-}=\min _{l}\left\{c_{\mathrm{lg}}\right\},
\end{aligned}
$$

where $c_{g}^{+}$and $c_{g}^{-}$denote the positive and negative ideal points of each evaluation indicator, respectively. The dominance $s_{l g}$ of the SACE indicator $c_{g}$ is calculated with the following equation:

$$
\begin{aligned}
& s_{\lg }=\frac{\left(c_{\lg }-c_{g}^{-}\right)^{2}}{\left(c_{\lg }-c_{g}^{+}\right)^{2}+\left(c_{\lg }-c_{g}^{-}\right)^{2}}, \\
& s_{\lg } \in[0,1] .
\end{aligned}
$$

Relative dominance matrix $S$ is constructed (see equation (12)) according to the dominance calculated with equation (11). Let $j$ denote the number of evaluated construction enterprises. Then,

$$
S(\lg )=\left(\begin{array}{cccc}
s_{11} & s_{12} & \ldots & s_{1 p} \\
s_{21} & s_{22} & \ldots & s_{2 p} \\
\vdots & \vdots & \ldots & \vdots \\
s_{j 1} & s_{j 2} & \ldots & s_{j p}
\end{array}\right) .
$$

The degree of competitive differentiation between construction enterprises in a given standardization ability category could be mirrored by the dominance of the SACE in each evaluation indicator. The competitiveness of construction enterprises reflected by the evaluation indicators is assessed using

$$
\begin{aligned}
& o_{\lg }=\frac{c_{\lg }\left(1+s_{\lg }\right)}{100}, \\
& o_{\lg } \in(0,2] .
\end{aligned}
$$

Construction enterprises with strong standardization ability show higher dominance in each evaluation indicator and receive higher evaluation values.

The relative competitiveness matrix, which is denoted as $O$, is obtained from equation (13); then, we have the following:

$$
O(\lg )=\left(\begin{array}{cccc}
o_{11} & o_{12} & \ldots & o_{1 p} \\
o_{21} & o_{22} & \ldots & o_{2 p} \\
\vdots & \vdots & \ldots & \vdots \\
o_{j 1} & o_{j 2} & \ldots & o_{j p}
\end{array}\right)
$$

(2) Identifying the Indicator Weights from the Perspective of Competitive Differentiation.

The main purpose of the dominance weighting method based on the perspective of competitive differences is to measure the degree of equilibrium in the standardization ability status of construction enterprises. The greater the weight of the evaluation indicator is, the more obvious the difference is. The characteristics of this weighting method are conducive to grasping the differences in competition intensity among different construction enterprises within each evaluation category, determining the key driving factors that promote the SACE, and providing a reference for how to boost the SACE as well. $v_{g}$ represents the degree of difference in the evaluated construction enterprise in category $c_{g}$, which is measured by the mean square deviation method:

$$
v_{g}=\sqrt{\frac{1}{j} \sum_{l=1}^{j}\left(o_{\mathrm{lg}}-\bar{o}_{g}\right)^{2}} .
$$

The difference level for each construction enterprise in evaluation category $c_{g}$ is explained by the size of $v_{g}$. The larger $v_{g}$, the greater the weight of the corresponding indicator and the more obvious the differences in the construction enterprises for indicator $c_{g}$. Construction enterprises with a low ability to standardize should be guided to high value resource investments in this indicator, which contributes to the improvement of the standardization ability level of construction enterprises and enhances the competitiveness of enterprises. The competitive differentiation weights for the indicators of standardization ability are

$$
w_{g}=\frac{v_{g}}{\sum_{g=1}^{p} v_{g}},
$$

where $w_{g}$ refers to the weight coefficient of evaluation indicator $c_{g}$ under competitive differentiation.

(3) Measurement Value of the Standardization Ability of Construction Enterprises considering Competitiveness.

The measurement value of the SACE was solved in line with the calculation process of the above weights:

$$
Y_{l}=\sum_{g=1}^{p} w_{g} c_{l g}
$$

where $w_{1}, w_{2}, \ldots, w_{p}$ represents the weight of each evaluation indicator and $Y_{l}$ represents the measurement value for the standardization ability of the evaluated construction enterprise $d_{l}$.

3.2.4. Measurement Value of the Standardization Ability of Construction Enterprises from the Dual Perspective. In summary, the comprehensive measurement value of the SACE included two parts: the demand-driven measurement value of the SACE and the competitive differentiation measurement value of the SACE.

$$
Z_{l}=\beta X_{l}+\gamma Y_{l}
$$

where $Z_{l}$ is the final evaluation value of the SACE and $\beta, \gamma \in[0,1]$, and satisfy $\beta+\gamma=1$. If $\beta=1$, then $Z_{l}=X_{l}$, which implies that the final evaluation value of the SACE is the demand-driven measurement value. If $\gamma=1$, then $Z_{l}=Y_{l}$, which implies that the final evaluation value of the SACE is the measurement value from the perspective of competitive differentiation. If $\beta, \gamma \in(0,1)$, it implies that the final evaluation value of the SACE is the combined value based on the dual perspective. This method is more flexible. 
3.2.5. Grade Division of the Standardization Ability of Construction Enterprises. The grade division reflects the degree to which the evaluated construction enterprises attach importance to the standardization ability category and the level of the SACE measured across different levels and dimensions. In accordance with the assessment content, referring to the opinions of senior executives and experts related to the field of standardization, combined with the division criteria from relevant references [72-74] and the specific comprehensive evaluation results in this study, the comprehensive evaluation of construction enterprises was divided into five grades, i.e., the evaluation set was set as $D=$ (very strong, comparatively strong, neutral, weak, very weak), as described in Table 1.

\section{Case Study}

\subsection{Data Collection and Processing}

4.1.1. Data Collection. The sample data for this paper were captured mainly via interviews and questionnaires. As a systematic data collection method, survey questionnaires have been extensively utilized in research on the construction industry $[75,76]$, which primarily adopts professional opinions on innovative issues [4].

Interviews: professionals (of different levels and positions and with different majors) in fields relevant to the enterprises were selected as the interviewees. These professionals have a deeper and more comprehensive grasp of the activities related to standardization work in an enterprise, which can effectively avoid potential bias in the interview process and can provide missing or complementary information at the same time based on the independent views of the same event held by different interviewees. The diversity of the interviewees guaranteed of accurate evaluation results would be acquired. Subsequently, additional research built upon the prior research was continuously carried out.

Questionnaire investigation: the questionnaire was composed of two parts. One part collected the attributes of the respondents, including professional title, specialized subject, and work tenure. The other part was the explanation of each assessment indicator, scoring criteria, and corresponding assignment. Questionnaires were administered to interviewees in a closed form (including the questions about characteristic attributes, the corresponding assignment of each indicator, and the grade range options) to gather survey data about indicator assignments.

In this paper, 20 construction enterprises were selected as cases to investigate the standardization ability. The data on each enterprise were derived from internal members of the enterprise (personnel in specific technical fields and management) to guarantee the integrity of the information and the richness of respondent experience. Additionally, experts (third-party members) in the field of construction engineering standardization were selected to accurately judge the scientific rationality of the standards adopted by enterprises from the aspects of contents, key technologies, indicators, and standard application of engineering construction standards while ensuring the objectivity of the evaluation process.
Twenty-two questionnaires were distributed to each investigated enterprise: 11 questionnaires were distributed to specialized technical personnel in key positions such as construction, safety, and quality in the construction enterprises; 5 and 4 were issued to personnel engaged in standardization work and senior managers in construction enterprises, respectively; and 2 were provided to external review experts in the standardization field. The proportion of questionnaires distributed was $50 \%, 22.73 \%$, and $18.18 \%$. In addition, all the interviewees held either a bachelor's degree or above, which ensured that the interviewees could effortlessly comprehend the assessment indicators and contents. Regarding work tenure, $54.5 \%$ of the employees had one to three years of work experience, $27.3 \%$ had three to five years of work experience, and $18.2 \%$ had five years or more of work experience.

4.1.2. Data Processing. The corresponding scoring criteria were set for the assessment contents of each evaluation indicator, and the statistical questionnaire was designed. Questionnaires were truthfully filled out by the investigated personnel, based mainly on the specific information covered in the open-ended interview and their own knowledge and experience. Depending on the relevant scoring criteria for each indicator, a seven-grade scoring system was employed to evaluate the indicators in the questionnaire ( 7 is the highest score, 1 is the lowest, and 2-6 indicate that the index score increases in turn). Finally, professionals with 5-10 years of experience in standardization work, who were researchers from scientific research institutions, professional managers in the industry, and reviewers of standardization work at Architectural Science Research Institute, were invited to pass judgment on the scoring of the evaluation indicators to ensure the reliability and accuracy of the collected data. The average score of each indicator in the evaluated construction enterprise was chosen as the final value of each indicator.

\subsection{Comprehensive Measurement of the Standardization Ability of Construction Enterprises}

4.2.1. Dimensionless Processing of Original Data. The accuracy of the comprehensive evaluation value is influenced by differences in the dimension and magnitude of the evaluation indicators. The stability of the proportional normalization method is not affected by the degree or direction of outliers deviating from the original value or large variations in the original data, and its stability was excellent [77]. Accordingly, the proportional method was selected to normalize the original data in this paper:

$$
c_{\mathrm{lg}}^{*}=\frac{c_{\mathrm{lg}}}{\max _{l}\left\{c_{\mathrm{lg}}\right\}},
$$

where $c_{\mathrm{lg}}$ denotes the initial value of evaluation indicator $c_{g}$ for evaluated construction enterprise $d_{l}$ and $c_{\mathrm{lg}}^{*}$ represents the data results after normalization. The normalized data are shown in Table 2 . The names of enterprises were replaced by serial numbers to protect privacy. 
TABLE 1: Evaluation set of the SACE.

\begin{tabular}{|c|c|c|c|c|c|c|c|c|c|c|c|c|}
\hline \multicolumn{2}{|c|}{ Grade of SA } & $\begin{array}{l}\text { Division } \\
\text { criteria }\end{array}$ & \multicolumn{10}{|c|}{ Assessment content } \\
\hline \multicolumn{2}{|c|}{ Very strong } & $(0.9,1)$ & \multicolumn{10}{|c|}{$\begin{array}{l}\text { CE attached great importance to SA; CE was in an excellent SAS and formulated the required } \\
\text { standards required on its own, strictly standardized the whole PPSA, and obtained extremely } \\
\text { considerable benefits. }\end{array}$} \\
\hline \multicolumn{2}{|c|}{$\begin{array}{l}\text { Comparatively } \\
\text { strong }\end{array}$} & $(0.7,0.9)$ & \multirow{2}{*}{\multicolumn{10}{|c|}{$\begin{array}{l}\text { CE attached importance to SA, SAS was better, requirements for technology and management were } \\
\text { rigorous, working state of PPSA was good, and considerable benefits were obtained. } \\
\text { CE attached some importance to SA. Either SAS or the working state of a certain practice process was } \\
\text { general, and moderate benefits were obtained. }\end{array}$}} \\
\hline \multicolumn{2}{|c|}{ Neutral } & $(0.5,0.7)$ & & & & & & & & & & \\
\hline \multicolumn{2}{|c|}{ Weak } & $(0.3,0.5)$ & \multicolumn{10}{|c|}{$\begin{array}{c}\text { CE had certain awareness of SA, but SAS was inferior, inadequate preparation for routine } \\
\text { standardization work, the application and implementation stages of PPSA were not in place, and the } \\
\text { effect of standardization activities was not noticeable. }\end{array}$} \\
\hline \multicolumn{2}{|c|}{ Very weak } & $(0,0.3)$ & \multicolumn{10}{|c|}{$\begin{array}{l}\text { CE thinks little of SA and had no requirements for SAS, working state of PPSA was inferior, and the } \\
\text { overall production level of CE was low. }\end{array}$} \\
\hline \multicolumn{13}{|c|}{$\begin{array}{l}\text { Note: SA represents the standardization ability; CE represents construction enterprise; SAS represents the state of adoption of standards; PPSA represents the } \\
\text { process of practicing standardization activities. }\end{array}$} \\
\hline \multirow{2}{*}{ SN } & \multirow{2}{*}{ D- } & \multirow{2}{*}{ S- } & \multirow{2}{*}{ I- } & \multirow{2}{*}{ DW } & \multirow{2}{*}{ CW } & \multicolumn{7}{|c|}{ Data after normalization of enterprises } \\
\hline & & & & & & CE 1 & CE 2 & CE 3 & $\ldots$ & CE 18 & CE 19 & CE 20 \\
\hline 1 & \multirow{11}{*}{$B_{1} 0.3191$} & \multirow{3}{*}{$c_{1} 0.5238$} & $c_{11}$ & 0.5425 & 0.0344 & 0.8349 & 0.7451 & 0.7860 & & 1.0000 & 0.5911 & 0.9048 \\
\hline 2 & & & $c_{12}$ & 0.2766 & 0.0378 & 0.8958 & 0.6671 & 0.8188 & $\ldots$ & 0.9495 & 0.5518 & 0.8681 \\
\hline 3 & & & $c_{13}$ & 0.1809 & 0.0337 & 1.0000 & 0.7572 & 0.7701 & $\ldots$ & 0.9100 & 0.6512 & 0.9129 \\
\hline 4 & & \multirow{3}{*}{$c_{2} 0.4762$} & $c_{21}$ & 0.3035 & 0.0376 & 0.6392 & 0.7084 & 0.6703 & $\ldots$ & 0.9701 & 0.5933 & 0.8793 \\
\hline 5 & & & $c_{22}$ & 0.2321 & 0.0339 & 0.7436 & 0.7197 & 0.6612 & $\ldots$ & 0.9162 & 0.5805 & 0.8926 \\
\hline 6 & & & $c_{23}$ & 0.4643 & 0.0316 & 0.9051 & 0.6974 & 0.6733 & $\ldots$ & 0.8201 & 0.6627 & 0.8274 \\
\hline 7 & & \multirow{5}{*}{$c_{3} 0.3409$} & $c_{31}$ & 0.1723 & 0.0344 & 0.9165 & 0.7738 & 0.9211 & $\ldots$ & 0.7527 & 0.6348 & 0.9206 \\
\hline 8 & & & $c_{32}$ & 0.1339 & 0.0351 & 0.9084 & 0.6887 & 0.8228 & $\ldots$ & 0.7275 & 0.5985 & 0.9818 \\
\hline 9 & & & $c_{33}$ & 0.2368 & 0.0358 & 0.9771 & 0.7498 & 0.9187 & $\ldots$ & 0.6136 & 0.5360 & 0.9193 \\
\hline 10 & & & $c_{34}$ & 0.1142 & 0.0360 & 0.9574 & 0.5568 & 0.8558 & $\ldots$ & 0.7744 & 0.5881 & 0.9184 \\
\hline 11 & & & $c_{35}$ & 0.3427 & 0.0343 & 0.9242 & 0.7402 & 0.8804 & $\ldots$ & 0.7260 & 0.5812 & 0.9788 \\
\hline 12 & & & $c_{41}$ & 0.4684 & 0.0348 & 0.9043 & 0.7855 & 0.9253 & $\ldots$ & 0.7531 & 0.6760 & 0.9621 \\
\hline 13 & & & $c_{42}$ & 0.1585 & 0.0326 & 0.8244 & 0.6749 & 0.8263 & $\ldots$ & 0.6613 & 0.6218 & 0.9727 \\
\hline 14 & & $\begin{array}{ll}c_{41} & 0.3750\end{array}$ & $c_{43}$ & 0.2559 & 0.0292 & 0.9126 & 0.9404 & 0.7839 & $\ldots$ & 0.8949 & 0.8704 & 0.9174 \\
\hline 15 & & & $c_{44}$ & 0.1172 & 0.0342 & 0.9777 & 0.9772 & 0.8466 & $\ldots$ & 0.8374 & 0.7729 & 0.9846 \\
\hline 16 & $B_{2} 0.4149$ & & $c_{51}$ & 0.2062 & 0.0240 & 0.9241 & 0.8961 & 0.8961 & $\ldots$ & 0.8748 & 0.8229 & 0.9258 \\
\hline 17 & & & $c_{52}$ & 0.1773 & 0.0312 & 0.9795 & 0.6951 & 0.8091 & $\ldots$ & 0.8231 & 0.7690 & 0.8913 \\
\hline 18 & & $c_{5} 0.2841$ & $c_{53}$ & 0.3546 & 0.0329 & 0.8936 & 0.6873 & 0.8566 & $\ldots$ & 0.9034 & 0.7043 & 0.9174 \\
\hline 19 & & & $c_{54}$ & 0.2621 & 0.0319 & 0.8806 & 0.6743 & 0.9535 & $\ldots$ & 0.7928 & 0.6665 & 0.8682 \\
\hline 20 & & & $c_{61}$ & 0.5426 & 0.0357 & 0.7819 & 0.8000 & 0.9159 & $\ldots$ & 0.7698 & 0.7770 & 0.9586 \\
\hline 21 & & $c_{6} 0.2591$ & $c_{62}$ & 0.1809 & 0.0319 & 0.9911 & 0.7248 & 0.8082 & $\ldots$ & 0.7259 & 0.6530 & 0.8134 \\
\hline 22 & & & $c_{63}$ & 0.2767 & 0.0346 & 0.7495 & 0.7267 & 0.9202 & $\ldots$ & 0.7346 & 0.7495 & 0.9078 \\
\hline 23 & & & $c_{71}$ & 0.2607 & 0.0336 & 0.9019 & 0.8398 & 0.8544 & $\ldots$ & 0.6929 & 0.7671 & 0.9473 \\
\hline 24 & & & $c_{72}$ & 0.1403 & 0.0335 & 1.0000 & 0.6605 & 0.7400 & $\ldots$ & 0.6443 & 0.6560 & 0.8103 \\
\hline 25 & $B_{3} 0.2659$ & $c_{7}$ & $c_{73}$ & 0.4209 & 0.0357 & 0.8355 & 0.7885 & 0.8189 & $\ldots$ & 0.6572 & 0.7761 & 0.9233 \\
\hline 26 & & & $c_{74}$ & 0.1783 & 0.0321 & 0.8813 & 0.7306 & 0.9003 & $\ldots$ & 0.6989 & 0.6526 & 0.8965 \\
\hline 27 & & & $c_{81}$ & 0.4684 & 0.0335 & 0.8558 & 0.7704 & 0.9392 & $\ldots$ & 0.7506 & 0.7746 & 0.9111 \\
\hline 28 & & & $c_{82}$ & 0.2559 & 0.0304 & 0.8488 & 0.6540 & 0.8703 & $\ldots$ & 0.8002 & 0.8040 & 0.9776 \\
\hline 29 & & $c_{8} 0.3368$ & $c_{83}$ & 0.1171 & 0.0300 & 0.8800 & 0.6808 & 0.7605 & $\ldots$ & 0.8263 & 0.8180 & 0.9154 \\
\hline 30 & & & $c_{84}$ & 0.1584 & 0.0335 & 0.9886 & 0.8962 & 0.9967 & $\ldots$ & 0.8192 & 0.7677 & 0.8916 \\
\hline
\end{tabular}

Note: S-, D-, and I- stand for subcategories, dimensions, and indicators, respectively; SN, DW, and CW denote the serial number, demand-driven capacity weight, and competitive differentiation weight, respectively.

4.2.2. Measuring the Standardization Ability of Construction Enterprises Based on Dominance and the Transformation Function
(1) Calculating the Weights for the Indicators of the Standardization Ability of Construction Enterprises. Solving the importance ratio for the indicators of the SACE: the order of 
importance for the evaluation indicators of the SACE at all levels in the indicator system was given in accordance with suggestions received from experts who are experienced in the engineering construction standard field and well-experienced researchers selected from scientific research institutions and institutions of higher learning. Taking the order of importance for the evaluation indicators in subcategory $c_{3}$ as an example, the hierarchy of the indicators is given as $c_{35}>c_{33}>c_{31}>c_{32}>c_{34}$, and the value of parameter $m$ obtained from equation (8) is 0.2295 , which was substituted into equation (3) to calculate the importance ratio between adjacent indicators in this subcategory: $R^{2}=[(5-1)+$ $1]^{0.2295}=1.4468, R^{3}=1.3746, R^{4}=1.2868$, and $R_{5}=1.1724$.

Calculating the weights for the indicators of standardization ability: in line with the importance ratios of the indicators calculated above, the weight of each indicator in subcategory $c_{3}$ was determined by using equations (4) and (5) and following the traditional G1 weighting method, namely, $u 5=(1+(1.4468 \times 1.3746 \times 1.2868 \times 1.1724+1.3746 \times 1.2868 \times$ $1.1724+1.2868 \times 1.1724+1.1724))-1=0.1142, u_{4}=u_{5} R_{5}=0$ $.1142 \times 1.1724=0.1339, u_{3}=u_{4} R_{4}=0.1339 \times 1.2868=0.17$ $23, u_{2}=u_{3} R_{3}=0.1723 \times 1.3746=0.2368$, and $u_{1}=u_{2} R_{2}=0$ $.2368 \times 1.4468=0.3427$.

Similarly, the order of importance for the three indicators in subcategory $c_{1}$ is $c_{11}>c_{12}>c_{13}$, and $R_{2}=1.9612$; $R_{3}=1.5295$; the order of importance for the three indicators included in subcategory $c_{2}$ is $c_{23}>c_{21}>c_{22}$, and $R_{2}=1.530 ; R_{3}=1.308$; the hierarchy of the four indicators in subcategory $c_{4}$ is $c_{41}>c_{43}>c_{42}>c_{44}$, and $R_{2}=1.8307$, $R_{3}=1.6148$, and $R_{4}=1.3530$; the hierarchy of the four indicators in subcategory $c_{5}$ is $c_{53}>c_{54}>c_{51}>c_{52}$, and $R_{2}=1.3530, R_{3}=1.2708$, and $R_{4}=1.1632$; the hierarchy of the three indicators in subcategory $c_{6}$ is $c_{61}>c_{63}>c_{62}$, and $R_{2}=1.9612 ; R_{3}=1.5295$; the order of importance for the four indicators in subcategory $c_{7}$ is $c_{73}>c_{71}>c_{74}>c_{72}$, and $R_{2}=1.6148, R_{3}=1.4620$, and $R_{4}=1.2708$; and the order of importance for the four indicators in subcategory $c_{8}$ is $c_{81}>c_{82}>c_{84}>c_{83}$, and $R_{2}=1.8307, R_{3}=1.6148$, and $R_{4}=1.3530$. The weights for the indicators were determined (see the fifth column of Table 2). The weights for the three primary dimensions and eight subcategories were calculated directly following the G1 weighting method. The results are listed in columns 2 and 3 of Table 2 .

(2) Measuring Standardization Ability. The demand-driven standardization ability of each of the evaluated construction enterprises in each subcategory was evaluated via equation (8). The results are shown in Table 3. Next, the comprehensive measurement value of the SACE was identified, as shown in column 8 of Table 4 .

\subsubsection{Measuring the Standardization Ability of Construction} Enterprises from the Perspective of Competitive Differentiation

(1) Calculating the Indicator Weights Based on Competitive Differentiation. Calculation of competitiveness in the relevant categories: the original data were normalized with equation (19) and then substituted into equation (10). The positive ideal point of each evaluation indicator for standardization ability is $c_{g}^{+}=(1.0000,1.0000, \ldots, 1.0000$, $1.0000)$, and the negative ideal point is $c_{g}^{-}=(0.59111,0.5518$ $, \ldots, 0.6737,0.7521)$, which reflects the competitiveness of the evaluated enterprise in all categories. The degree of dominance for all the evaluated enterprises in each category was calculated using equation (11), and relative dominance matrix $S$ was constructed:

$$
S(\lg )_{20 \times 30}=\left(\begin{array}{ccccc}
0.6856 & 0.9159 & 1.0000 & \cdots & 0.9977 \\
0.2674 & 0.1071 & 0.1791 & \cdots & 0.6582 \\
\vdots & \vdots & \vdots & \vdots & \vdots \\
0.0000 & 0.0000 & 0.0004 & \cdots & 0.0045 \\
0.9157 & 0.8519 & 0.9052 & \cdots & 0.6234
\end{array}\right) \text { CE } 2
$$

The competitiveness of the evaluated construction enterprises in all categories of standardization ability was calculated using equation (13), and relative competitiveness matrix $O$ was also constructed:

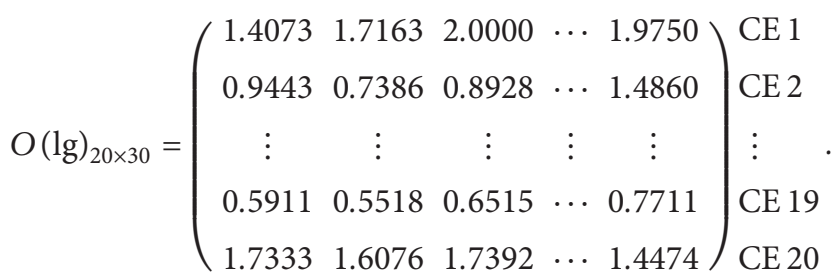

Calculating the competitive differentiation weights for the indicators of standardization ability: the mean squared deviation of the relative competitiveness of each evaluated construction enterprise, which reflected the competitiveness of the enterprises in 30 categories of standardization ability, was determined using equation (15). The weight for each competitive differentiation indicator of the SACE was calculated with equation (16), as shown in column 6 of Table 2 .

(2) Measuring Standardization Ability. The 10th column of Table 4 shows the comprehensive evaluation of the SACE from the perspective of competitive differentiation, calculated with equation (17).

4.3. Final Comprehensive Measurement of the Standardization Ability of Construction Enterprises. Equation (18) was used to calculate the final evaluation of the SACE from the perspectives of demand-driven capacity and competitive differentiation. Take $\beta=0.5$ (so that $\gamma=0.5$ ). The final results are specified in the penultimate column of Table 4.

\section{Results and Discussion}

5.1. Analysis of the Standardization Ability of Construction Enterprises along Various Dimensions. The bar chart shown in Figure 5, based on the results in Table 4, shows the following:

(1) Few enterprises that had low scores in specific dimensions were highly ranked in the comprehensive 
TABLE 3: Evaluation of the demand-driven standardization ability of the construction enterprises in each subcategory.

\begin{tabular}{|c|c|c|c|c|c|c|c|c|c|c|c|c|c|c|c|c|}
\hline $\mathrm{CE}$ & Eval $c_{1}$ & R- & Eval $c_{2}$ & $\mathrm{R}-$ & Eval $c_{3}$ & R- & Eval $c_{4}$ & R- & Eval $c_{5}$ & $\mathrm{R}-$ & Eval $c_{6}$ & R- & Eval $c_{7}$ & R- & Eval $c_{8}$ & R- \\
\hline 1 & 0.8816 & 6 & .7868 & 12 & 0.9370 & 5 & 0.9024 & 10 & 0.9119 & 6 & 0.8109 & 14 & 0.8842 & 9 & .8777 & 13 \\
\hline 2 & 0.7257 & 15 & .7058 & 16 & .7203 & 17 & 0.8301 & 16 & .7285 & 20 & .7663 & 16 & 0.7738 & 15 & .7499 & 18 \\
\hline 3 & 0.7922 & 13 & 0.6695 & 17 & 8859 & 8 & .8642 & 12 & 0.8819 & 9 & .8978 & 7 & 0.8318 & 13 & .9096 & 7 \\
\hline 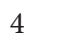 & 0.7227 & 16 & 0.6639 & 18 & 0.8923 & 7 & 0.9225 & 8 & 0.9208 & 4 & 0.8039 & 15 & 0.7736 & 16 & 0.9003 & 9 \\
\hline 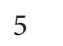 & 0.6239 & 19 & 0.7074 & 15 & 0.8342 & 12 & 0.7846 & 18 & 0.8120 & 16 & 0.7229 & 20 & 0.6638 & 20 & 0.6896 & 20 \\
\hline 6 & 0.6526 & 18 & 0.6569 & 19 & 0.6459 & 19 & 0.7354 & 19 & 0.7954 & 18 & 7601 & 17 & .7065 & 18 & 0.7260 & 19 \\
\hline 7 & 0.9583 & 3 & 347 & 2 & 0.8377 & 11 & 0.9279 & 7 & 0.8495 & 13 & 636 & 9 & 051 & 6 & 283 & 4 \\
\hline 8 & 0.8729 & 7 & 0.8288 & 10 & 0.9724 & 2 & 0.9872 & 1 & 0.9272 & 3 & 0.9396 & 3 & 0.9815 & 1 & .9811 & 2 \\
\hline 9 & 0.6846 & 17 & 0.8297 & 9 & 307 & 1 & 0.8 & 14 & 09 & 17 & 60 & 8 & 47 & 11 & 030 & 8 \\
\hline 10 & 8458 & 9 & & 4 & & 10 & & 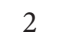 & & 5 & & 4 & & & 95 & 15 \\
\hline 11 & 0.8390 & 10 & 7576 & 13 & 59 & 13 & 57 & 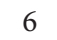 & 95 & 10 & 085 & 6 & 903 & 8 & 3629 & 14 \\
\hline 12 & 0.8597 & 8 & 0.7461 & 14 & 0.7730 & 15 & 0.8943 & 11 & 0.8279 & 14 & & 13 & & 12 & 0.8827 & 11 \\
\hline 13 & 0.9656 & 2 & 0.9561 & 1 & 0.8799 & 9 & 0.9185 & 0 & 0.8903 & 8 & 0.9460 & 2 & 0.9570 & 3 & 9603 & 3 \\
\hline 14 & 0.8138 & 11 & & 6 & & 4 & & 3 & & 2 & & 1 & & 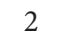 & 185 & 6 \\
\hline 15 & 0.8833 & 5 & 095 & 3 & 361 & 6 & 393 & 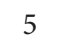 & 00 & 1 & 331 & 12 & 0.9346 & 4 & .9836 & 1 \\
\hline 16 & 0.7543 & 14 & 0.7895 & 11 & 0.7526 & 16 & 0.8481 & 15 & 0.8515 & 12 & 0.8350 & 11 & 0.8993 & 7 & 0.8989 & 10 \\
\hline 17 & 0.8064 & 12 & 0.8451 & 8 & 0.8164 & 14 & 0.8602 & 13 & 0.8168 & 15 & 0.8535 & 1 & 0.8513 & 10 & 0.8796 & 12 \\
\hline 18 & 0.9698 & 1 & 0.8878 & 5 & 0.7096 & 18 & 0.7847 & 17 & & 11 & 0.7523 & 18 & 0.6723 & 19 & 0.7829 & 17 \\
\hline 19 & 0.5911 & 20 & 0.6225 & 20 & 0.5828 & 20 & 0.7285 & 20 & 0.7305 & 19 & 0.7471 & 19 & 0.7350 & 17 & 0.7859 & 16 \\
\hline 20 & 0.8961 & 4 & 0.8582 & 7 & 0.9481 & 3 & 0.9550 & 4 & 0.9018 & 7 & 0.9185 & 5 & 0.9091 & 5 & 0.9253 & 5 \\
\hline
\end{tabular}

Note: Eval stands for the evaluation value; R- stands for ranking.

TABLE 4: Comprehensive evaluation of the SACE.

\begin{tabular}{|c|c|c|c|c|c|c|c|c|c|c|c|}
\hline \multicolumn{9}{|c|}{ Demand-driven } & \multirow{2}{*}{$\begin{array}{l}\text { Competitive differentiation } \\
\text { Comprehensive Eval }\end{array}$} & \multicolumn{2}{|c|}{ Final Eval } \\
\hline $\mathrm{CE}$ & Eval $B_{1}$ & $\mathrm{R}-$ & Eval $B_{2}$ & $\mathrm{R}-$ & Eval $B_{3}$ & $\mathrm{R}-$ & Comprehensive Eval & $\mathrm{R}-$ & & Final Eval & $\mathrm{R}-$ \\
\hline 1 & 0.8365 & 8 & 0.9169 & 6 & 0.8631 & 11 & 0.8768 & 8 & 0.8888 & 0.8828 & 7 \\
\hline 2 & 0.7162 & 16 & 0.7638 & 18 & 0.7639 & 16 & 0.7486 & 17 & 0.7450 & 0.7468 & 17 \\
\hline 3 & 0.7338 & 15 & 0.8766 & 11 & 0.8752 & 9 & 0.8306 & 12 & 0.8398 & 0.8352 & 12 \\
\hline 4 & 0.6947 & 17 & 0.9117 & 7 & 0.8242 & 15 & 0.8191 & 15 & 0.8313 & 0.8252 & 14 \\
\hline 5 & 0.6637 & 18 & 0.8093 & 16 & 0.6879 & 20 & 0.7305 & 18 & 0.7391 & 0.7348 & 18 \\
\hline 6 & 0.6546 & 19 & 0.7219 & 19 & 0.7270 & 19 & 0.7017 & 19 & 0.7107 & 0.7062 & 19 \\
\hline 7 & 0.9471 & 2 & 0.8749 & 12 & 0.9023 & 6 & 0.9051 & 6 & 0.8902 & 0.8977 & 6 \\
\hline 8 & 0.8519 & 7 & 0.9651 & 1 & 0.9706 & 1 & 0.9303 & 2 & 0.9395 & 0.9349 & 1 \\
\hline 9 & 0.7537 & 14 & 0.8870 & 9 & 0.8751 & 10 & 0.8412 & 10 & 0.8552 & 0.8482 & 10 \\
\hline 10 & 0.8659 & 6 & 0.9188 & 5 & 0.8431 & 14 & 0.8817 & 7 & 0.8833 & 0.8825 & 8 \\
\hline 11 & 0.8002 & 12 & 0.8795 & 10 & 0.8859 & 7 & 0.8558 & 9 & 0.8599 & 0.8579 & 9 \\
\hline 12 & 0.8056 & 11 & 0.8341 & 13 & 0.8505 & 13 & 0.8293 & 13 & 0.8257 & 0.8275 & 13 \\
\hline 13 & 0.9611 & 1 & 0.8973 & 8 & 0.9554 & 3 & 0.9330 & 1 & 0.9220 & 0.9275 & 3 \\
\hline 14 & 0.8357 & 9 & 0.9589 & 2 & 0.9555 & 2 & 0.9186 & 4 & 0.9239 & 0.9213 & 4 \\
\hline 15 & 0.8958 & 4 & 0.9554 & 3 & 0.9249 & 4 & 0.9282 & 3 & 0.9277 & 0.9280 & 2 \\
\hline 16 & 0.7711 & 13 & 0.8165 & 15 & 0.8826 & 8 & 0.8195 & 14 & 0.8173 & 0.8184 & 15 \\
\hline 17 & 0.8248 & 10 & 0.8329 & 14 & 0.8615 & 12 & 0.8378 & 11 & 0.8338 & 0.8358 & 11 \\
\hline 18 & 0.9308 & 3 & 0.7789 & 17 & 0.7303 & 18 & 0.8144 & 16 & 0.7934 & 0.8039 & 16 \\
\hline 19 & 0.6061 & 20 & 0.6794 & 20 & 0.7554 & 17 & 0.6762 & 20 & 0.6846 & 0.6804 & 20 \\
\hline 20 & 0.8781 & 5 & 0.9375 & 4 & 0.9171 & 5 & 0.9130 & 5 & 0.9134 & 0.9132 & 5 \\
\hline
\end{tabular}

evaluation. Rather, some enterprises were higher ranked in the evaluation of individual dimensions, but their ultimate comprehensive evaluation was still unsatisfactory. The reason for this is that the construction enterprises paid different levels of attention to standardization activities or had differences in their characteristics and resource inputs.

The comprehensive evaluation of the three primary dimensions for the 20 enterprises was compared and analyzed. The overwhelming majority of the evaluations of each dimension was above the grade "comparatively strong," and the number of enterprises whose evaluations of $B_{1}, B_{2}$, and $B_{3}$ were above 0.80 was 12,16 , and 15 , respectively. Typically, enterprise 4 received a generally low evaluation in the quality dimension, while it received a higher evaluation in the process and benefit dimensions, which is reflective of more inputs into implementation. The proportion of the weight placed on the process dimension was larger than that placed on the quality and benefit dimensions. Analogously, the evaluation results for enterprises 6 and 8 in the quality 


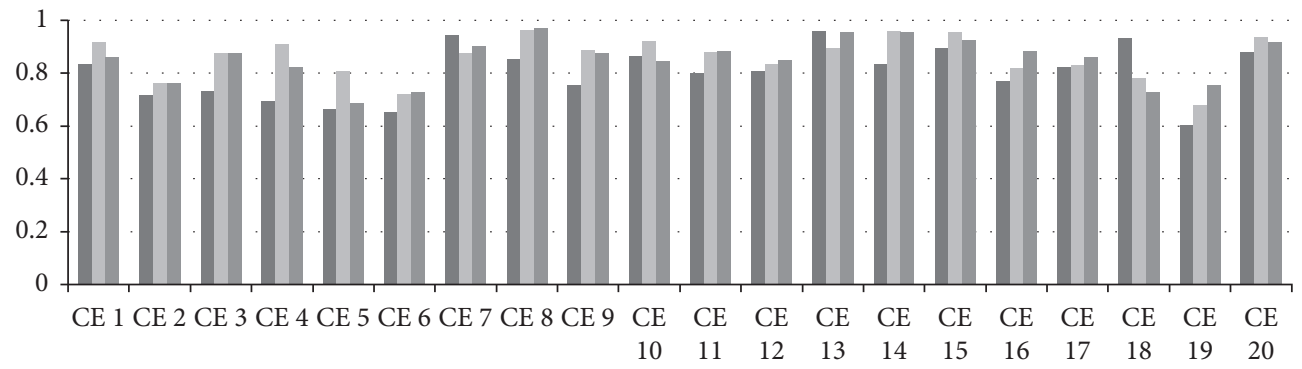

$$
\begin{array}{r}
\text { EVQD } \\
\text { EVPD } \\
\text { - EVBD }
\end{array}
$$

FIGURE 5: Evaluation results for the primary dimensions. EVQD, EVPD, and EVBD denote the evaluation of the quality dimension, process dimension, and benefit dimension from the perspective of demand-driven capacity, respectively.

dimension were also lower than those in the other two dimensions. In contrast, the state of standards adoption in enterprises 7 and 13 was excellent, which was also reflected in considerable benefits, but their process dimension was mediocre. Enterprise 18 attached great importance to the state of its standards adoption, but less energy was invested in the other two dimensions, which was not conducive to the improvement of its overall production level. However, the final evaluation results were all relatively high, indicating that these enterprises still valued standardization ability highly. Enterprises 6 and 19 emphasized standardization ability by improving the effects of the standardization activities, even though the final evaluation of standardization ability is based on the overall level, which indicates that the SACE is continuously weakened when few inputs are invested in the quality and process dimensions. Therefore, different enterprises paid different levels of attention to standardization work in different dimensions, which led to different levels of effort in various aspects.

(2) There was a large gap between $B_{1}$ and $B_{2}$ in the SACE, and there were obvious fluctuations. The enterprise with the highest value for $B_{1}$ was 13 (0.9611), while the enterprise with the lowest value was $19(0.6061)$, with a difference of 0.36 . There was a difference of 0.29 between enterprise 8 , which had the highest value of $B_{2}$, and enterprise 19 , which had the lowest value. Additionally, the value of $B_{3}$ for enterprise 8 was ranked first, which shows that this enterprise took the process of practicing standardization activities seriously and that its ability to promote the development of technology, economy, and society was strong. Only enterprises 7, 13, and 18 had the evaluation results for $B_{1}$ that were higher than those for $B_{2}$, while the values for enterprises 12 and 17 in the three primary dimensions were the most balanced.

(3) The SACE was closely correlated with the three primary dimensions. It can be observed from the ranking of each dimension in Table 3 that the comprehensive evaluation of the SACE was bound up with the evaluation of each dimension, i.e., the ranking of the comprehensive evaluation results from the perspective of demand-driven capacity was affected by the ranking for each dimension. The ranking of enterprise 6 in the three primary dimensions was completely consistent with its comprehensive ranking; enterprises 20, 12, and 19 were each ranked the same in two of the main dimensions, which was only 1, 2, and 3 places from each of their rankings in the other dimension, respectively. Their comprehensive ranking was in line with the rankings they received in the two primary dimensions that were the same. This might suggest that an excellent evaluation in the three main dimensions always translated to a strong standardization ability; however, the standardization ability was weak.

The technological, quality, and economic advantages of standardization for enterprises lie in the fact that standardization normalizes their production and operation activities through quality regulations on many matters that need to be coordinated and unified, which results in orderly and standardized activities in all stages of construction [43]. The level of the SACE was determined by the resultant synergy among the quality, process, and benefit dimensions.

\subsection{Analysis of the Standardization Ability of Construction Enterprises}

(1) Figure 6 is based on the final evaluation results in Table 4 . The evaluation of the SACE was inconsistent. The comprehensive measurement results in Table 4 show the level of the SACE (evaluation results were concentrated in the range of $0.65-0.95)$. Most of the evaluations were greater than 0.80 , which demonstrated that the standardization ability was comparatively strong.

As seen from Table 4 and Figure 6, enterprises 8, 13, 14 , and 15 ranked as the top four enterprises in standardization ability among all the evaluated enterprises, with evaluations higher than 0.9. From the 


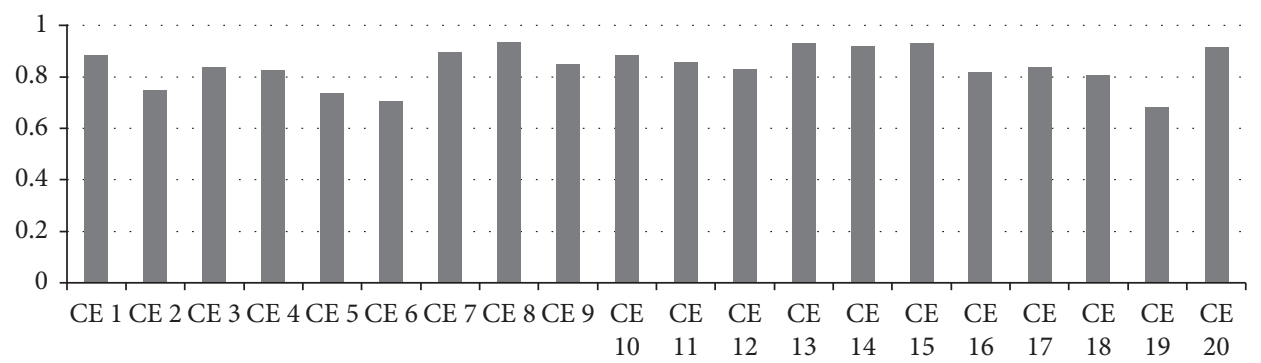

Figure 6: Final measurement of the SACE.

matrix of relative dominance and relative competitiveness, it is obvious that the strong advantages and competitiveness of these enterprises were highlighted in the SACE indicators, which was inevitably spurred by the external environment (competition among enterprises prompted the development of standardization activities, and thereby, the level of competition was enhanced [15]). Enterprises 13, 14, and 15 "kept pace with each other"; however, enterprises 6 and 19 were given the lowest evaluations, which were relatively low compared with those of the other enterprises. Moreover, as enterprises whose dual-perspective evaluations were lower than 0.7 , their comprehensive evaluation ranked at the bottom of the list. There was a difference of 0.26 between the enterprises with the lowest values and those with the highest values, which is still a wide gap. Targeted measures should be taken to elevate the level of the low-ranked enterprises' standardization ability.

(2) Taking the measurement from the perspective of demand-driven capacity as the horizontal axis and the measurement from the perspective of competitive differentiation as the vertical axis, a rectangular coordinate system was established (see Figure 7), with the origin representing the intersection of the comprehensive demand-driven value with the comprehensive competitive differentiation value at 0.85 and 0.75 , respectively.

The values from both perspectives for all enterprises were plotted in the rectangular coordinate system and were fitted with a straight line: $y=0.97 x+0.03$, which is close to $y=x$, and $R^{2}>0.95$, which suggests that the evaluations calculated from the dual perspective provided extremely similar results. The input of some specific indicators of the SACE was not found to be overemphasized.

In Figure 7, the SACE was divided into three echelons. The first type is represented by enterprises 8 , 13 , and 15 , which are located in the first quadrant and constitute the "first echelon" of the SACE. The comprehensive evaluations of these enterprises from the perspectives of demand-driven capacity and competitive differentiation were higher and were obviously superior to those of approximately half of all other enterprises. These three representative enterprises were also labeled as having a strong standardization ability, ranking in the top three, as shown in Figure 6. Enterprise 8 took the lead among all construction enterprises. These construction enterprises place a high value on their own standardization ability level, and their overall production and operation level is excellent, which is reflected in a high level of competitiveness. The second category is represented by enterprises 3,4 , and 9 , located in the second quadrant, which together constitute the "second echelon." The comprehensive evaluation of these enterprises from the perspective of competitive differentiation was relatively high, while their performance from the perspective of demand-driven capacity was relatively low. The third is represented by enterprises $2,5,6$, and 19 , located in the third quadrant, which indicates that the comprehensive evaluations of these enterprises were at a low level from both perspectives. Moreover, Figure 6 shows that the final evaluation of the standardization ability of these four enterprises was ranked in the last four places, and their comprehensive development level was similar to the average. These enterprises need to strengthen their investment in many aspects. A lack of standards adoption and standardization activities in the early stages leads to flat performance in benefit generation, which inevitably affects the comprehensive standardization ability of the enterprise.

5.3. Analysis of the Relationship between the Three Primary Dimensions. To clarify the relationship between $B_{1}, B_{2}$, and $B_{3}$, the benefit dimension $B_{3}$ was chosen to be the dependent variable $y_{c}$, and the quality dimension $B_{1}$ and process dimension $B_{2}$ were deemed independent variables $x_{a}$ and $x_{b}$, respectively, for a multiple linear regression analysis. Using the above variables, the effects of the standardization activities of enterprises (the benefit dimension) were modeled as follows:

$$
y_{c}=\alpha_{0}+\alpha_{1} x_{a}+\alpha_{2} x_{b}+\omega,
$$

where $x_{a}$ and $x_{b}$ are the two independent variables representing the quality dimension and process dimension, respectively, and $y_{c}$ represents the benefit dimension (the dependent variable). In this paper, 20 construction enterprises have been empirically studied, and the data are taken from Table 4. This analysis is not the focus of this paper, so we do 


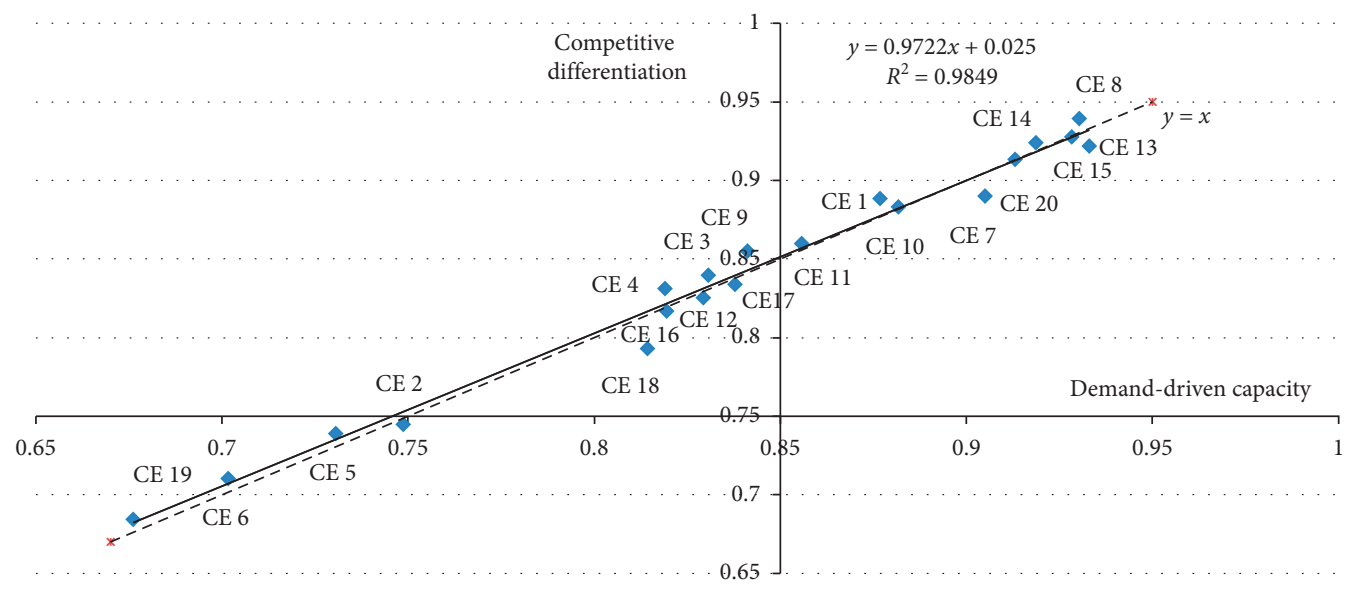

Figure 7: Distribution of the dual-perspective evaluations of the enterprises.

not provide a detailed description. SPSS 25.0 was utilized to conduct the multiple linear regression analysis, and the correlations among the three variables were analyzed. The results showed that the correlation between $B_{1}$ and $B_{2}$ was 0.600 and that between $B_{1}$ and $B_{3}$ was 0.620 , which is a moderate correlation in both cases. The correlation between $B_{2}$ and $B_{3}$ was 0.803 , which is a strong correlation. Furthermore, the three variables were positively correlated with each other. The multiple correlation coefficient $R$ of the model was 0.822 , the sample coefficient of determination $R^{2}$ was 0.675 , and adjusted $R^{2}$ was 0.637 . The regression model has a high level of explanatory power. The Durbin-Watson value was close to 2 , and there was no correlation between the residual terms in the model. The $F$-value corresponding to the regression variance was 17.681 , and its significance was 0.000 , less than 0.005 . This demonstrated that the established regression equation was effective. The VIF was relatively close to 1 , and multicollinearity among the explanatory variables was weak. Therefore, there were obvious interaction effects among the three primary dimensions. Moreover, these results verify the description of the three elements of the SACE given in Section 3.1, i.e., the three elements interacted with each other (circular interaction around the goal), and the SACE was jointly promoted under their synergistic effect.

The quality dimension (status of adopting standards in enterprises) represents the promotion and implementation of the engineering construction standards adopted by the enterprises, which are the basis for carrying out production and operation activities [15] and which have a direct impact on the overall process of efficiently implementing the standards, while the benefit dimension (the effects of standardization activities) is restricted to a certain extent. The process of practicing standardization activities (process dimension) transforms the standards into actual effects by using various means to achieve performance goals, which have a direct impact on the effect of standardization activities and are counter-reflected in the quality dimension; that is, the problems encountered during the practice process could be used to guide enterprises in the selection and perfection standards. The effects of the standardization activities (benefit dimension) are directly and indirectly affected by the process of practicing standardization activities (process dimension) and the status of standards adoption in enterprises (quality dimension); this is also counter-reflected in both concurrently. Strategies for selecting and revising the engineering construction standards and improving and adjusting the practice process should be made by judging the benefits generated within the enterprise. The relationship among the three dimensions is displayed in Figure 8.

\subsection{Analysis of the Comprehensive Measurement Model for the} Standardization Ability of Construction Enterprises. Building on actual needs, a comprehensive measurement model of the SACE from a dual perspective was designed, which is conducive to the advancement of the SACE. The results show that the SACE is a dynamic system that is affected by the synergy among three primary dimensions, consisting of the quality dimension, process dimension, and benefit dimension. Volatility (or imbalance) in the final evaluation occurs if one of the dimensions changes. In addition, there are relationships among the eight subcategories that comprise the SACE. These results suggest that decision makers and personnel responsible for standardization work should pay attention to the coordination among the three dimensions and eight subcategories instead of emphasizing economic variables such as profit and output values. This study provides a measurement model that the relevant decision makers can use to evaluate and reasonably rank standardization ability, determine the weak links hindering the development of the enterprise, identify competitive advantages, and then perfect their standardization ability.

Following the principle of index selection, it is very important to select main indicators that affect the achievement of the objective. More factors could be considered or eliminated according to knowledge and experience. How to overcome these subjective factors 


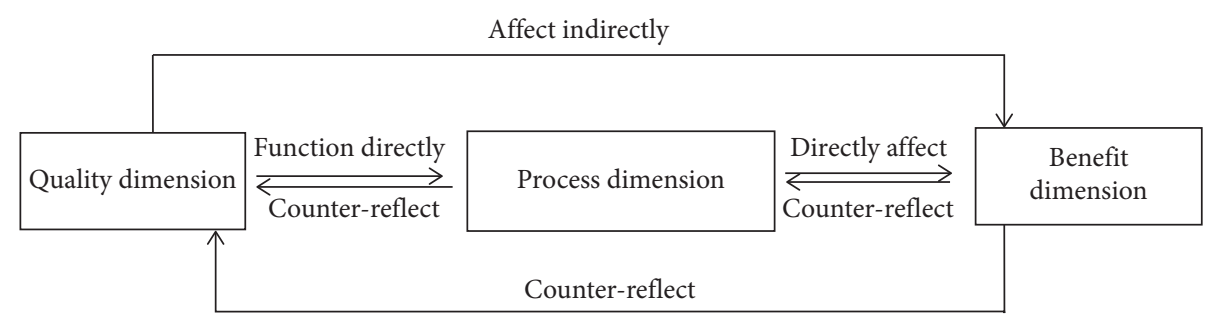

FIGURE 8: The model of the relationship among the three primary dimensions.

needs to be further explored in future research. Further studies will explore the internal mechanisms and paths between the core elements of standardization ability.

\section{Conclusions}

The improvement of the SACE occurred via the coordinated development of various dimensions and subcategories. The key to improving the SACE is to explore the core elements affecting the SACE and to analyze the importance of each factor (or indicator) to the enterprise. This study aimed to design a set of scientific and systematic indicator libraries of standardization ability and a comprehensive measurement model from the dual perspective of demand-driven capacity and competitive differentiation.

The SACE index system was the hinge for the evaluation of the SACE. The division of the index levels was achieved through a process of reviewing the literature, conducting systematic analyses, and conducting interviews. A total of 30 indicators that fell into eight subcategories were identified to evaluate the SACE. The indicator system established in this study provides a set of measurement tools for enterprises to evaluate their standardization ability. Moreover, the indicator system constructed in this paper is conducive to expanding the action mechanisms, associated relationships, and functional paths of the core elements (the three primary dimensions). The interaction effect among the three dimensions was further analyzed to clarify the key drivers of the advancement of standardization ability.

The comprehensive measurement model in this paper, constructed based on a dual perspective and meeting the actual demand for evaluation, can effectively evaluate the SACE. The validity of the model was verified via the case analysis of the selected construction enterprises, which can guide the practical improvement of standardization ability for similar situations, promote competitive behavior, and guarantee the standardization of enterprises [78]. This model can be used by decision makers to evaluate the SACE, formulate corresponding incentive measures, and detect defects in practice.

Multiple linear regression analysis showed that there were obvious interactions and correlations among the three primary dimensions. This is consistent with the conclusion that the SACE was affected by the synergy of the three dimensions. Additionally, the description of its core elements (the interplay of three elements) in Section 3.1 was also verified, which indicates that it is reasonable to measure the SACE along the three dimensions: quality, process, and benefits. To promote the development of enterprises, decision makers should pay more attention to the coordination among various dimensions, improve the standardization ability reflected in each dimension, and advance the comprehensive development of enterprises.

The research in this paper provides a reference for decision makers to select scientific and rational engineering construction standards and to improve the applicability of these standards to enterprises; it points out directions for flexibility in and the validity of implementing standards for staff engaged in a series of standardization activities in the enterprise; it also clarifies the degree of benefits the enterprise has obtained from standardization, that is, the impact of standardization on the relevant beneficiary groups, which provides a path to improve the comprehensive development ability of the enterprise.

The innovation and characteristics of this paper mainly lie in three components. First, on the basis of the three-stage measurement method and comprehensive evaluation theory, a multidimensional and multilayer indicator system for the SACE was constructed (see Figure 3). These dimensions were further divided into eight subcategories to jointly capture the SACE. The design of the measurement system summarized the major characteristics of the enterprises. Second, according to the actual needs of evaluation, the combination weighting method under the dual perspective overcame the limitations of the incompleteness of the evaluation perspective in existing studies. This method is more flexible.

There are limitations that will be addressed in the future. Although it is critical that key indicators are selected [79], the selection of indicators for standardization ability mostly relied on subjective experiences, which could be based on objective criteria to reduce the influence of subjective factors. The action mechanism and function path among the core elements need to be analyzed insightfully to make the improvement of the SACE more targeted. When the SACE was comprehensively measured from the dual perspective, the distribution of the weight coefficients for the combination weighting was not objective, which does not effectively reflect the difference of evaluation methods of standardization ability from a dual perspective.

\section{Data Availability}

The data used to support the findings of this study are included within the article. 


\section{Conflicts of Interest}

The authors declare that there are no conflicts of interest regarding the publication of this paper.

\section{Acknowledgments}

This research was supported by the Key Technology Project of the Transportation Industry in 2019: research and application of UAV ultralow altitude remote sensing technology in intelligent management of the $\mathrm{Ba}$ expressway construction (no. 2019-ZD5-028). The authors wish to express their thanks to all supporters.

\section{References}

[1] R. Spence and H. Mulligan, "Sustainable development and the construction industry," Habitat International, vol. 19, no. 3, pp. 279-292, 1995.

[2] N. Wang, "The role of the construction industry in China's sustainable urban development," Habitat International, vol. 44, pp. 442-450, 2014.

[3] R. D. Chang, J. Zuo, V. Soebarto, Z. Y. Zhao, G. Zillante, and X. L. Gan, "Discovering the transition pathways toward sustainability for construction enterprises: importance-performance analysis," Journal of Construction Engineering \& Management, vol. 143, no. 6, pp. 4017011-4017013, 2017.

[4] N. Dong, Y. Fu, F. Xiong, L. Li, Y. Ao, and I. Martek, "Sustainable construction project management (SCPM) evaluation-a case study of the Guangzhou metro line-7, PR China," Sustainability, vol. 11, no. 20, Article ID 5731, 2019.

[5] H. Xue and S. J. Zhang, "Relationships between engineering construction standards and economic growth in the construction industry: the case of China's construction industry," KSCE Journal of Civil Engineering, vol. 22, no. 5, pp. 16061613, 2018.

[6] H. Jiang, S. Zhao, Z. Zhang, and Y. Yi, "Exploring the mechanism of technology standardization and innovation using the solidification theory of binary eutectic alloy," Technological Forecasting and Social Change, vol. 135, pp. 217-228, 2018.

[7] T. Weitzel, D. Beimborn, and W. König, "A unified economic model of standard diffusion: the impact of standardization cost, network effects, and network topology," MIS Quarterly, vol. 30, pp. 489-514, 2006.

[8] Z. Xie, J. Hall, I. P. McCarthy, M. Skitmore, and L. Shen, "Standardization efforts: the relationship between knowledge dimensions, search processes and innovation outcomes," Technovation, vol. 48-49, pp. 69-78, 2016.

[9] A. R. Chini and H. E. Valdez, "ISO 9000 and the U.S. construction industry," Journal of Management in Engineering, vol. 19, no. 2, pp. 69-77, 2003.

[10] D. M. Zeng, Y. W. Wu, and W. H. Wu, "Construction of index system of technical standardization ability of enterprises," Science and Technology Management Research, no. 8, pp. 168-171, 2005.

[11] S. An, S. Ji, C. Hyun, and S. Han, “A model-based productivity improvement of reinforced concrete work in a multi-housing project," KSCE Journal of Civil Engineering, vol. 19, no. 5, pp. 1183-1192, 2015.

[12] P. Wakke, K. Blind, and F. Ramel, "The impact of participation within formal standardization on firm performance,"
Journal of Productivity Analysis, vol. 45, no. 3, pp. 317-330, 2016.

[13] H. Liu and G. Tian, "Building engineering safety risk assessment and early warning mechanism construction based on distributed machine learning algorithm," Safety Science, vol. 120, pp. 764-771, 2019.

[14] S. M. Besen and J. Farrell, "Choosing how to compete: strategies and tactics in standardization," Journal of Economic Perspectives, vol. 8, no. 2, pp. 117-131, 1994.

[15] C. Chen and C. Liu, "Empirical research on the relationship between standardization and technological progress in the internal compliance," Finance Issues, vol. 12, pp. 36-40, 2008.

[16] S. Rosenbaum, M. Toledo, and V. Gonzalez, "Improving environmental and production performance in construction projects using value-stream mapping: case study," Journal of Construction Engineering \& Management, vol. 140, no. 2, pp. 4013041-4013045, 2014.

[17] D. Zhang, H. Nasir, and C. T. Haas, "Development of an internal benchmarking and metrics model for industrial construction enterprises for productivity improvement," Canadian Journal of Civil Engineering, vol. 44, no. 7, pp. 518-529, 2017.

[18] Y. Y. Feng, S. L. Hao, and R. J. Ding, "Enterprise standardization management mode and operation mechanism," Forum on Science and Technology in China, no. 6, pp. 77-82, 2014.

[19] K. Blind and A. Jungmittag, "The impact of patents and standards on macroeconomic growth: a panel approach covering four countries and 12 sectors," Journal of Productivity Analysis, vol. 29, no. 1, pp. 51-60, 2008.

[20] A. A. Bubshait and T. H. Al-Atiq, "ISO 9000 quality standards in construction," Journal of Management in Engineering, vol. 15, no. 6, pp. 41-46, 1999.

[21] C. J. Gong, P. T. Yi, and W. W. Li, "Research on evaluation method of provincial science and technology development level based on dual driven," Studies in Science of Science, vol. 37, no. 9, pp. 1589-1597, 2019.

[22] D. Wang, X. Wei, and F. Fang, "The resource evolution of standard alliance by technology standardization," Chinese Management Studies, vol. 10, no. 4, pp. 787-801, 2016.

[23] H. Jiang, S. Zhao, S. Zhang, and X. Xu, "The adaptive mechanism between technology standardization and technology development: an empirical study," Technological Forecasting and Social Change, vol. 135, pp. 241-248, 2018.

[24] S. K. Zhao, X. W. Ju, and X. F. Lu, "A study on mechanism of the influence of technical standardization on industrial competitive advantage in China," China Soft Science, no. 1, pp. 13-17, 2004.

[25] F. Fang, K. Dickson, and D. Wang, "The standardization model of innovation: case of high-technology enterprises," Chinese Management Studies, vol. 10, no. 1, pp. 102-118, 2016.

[26] A. A. Techatassanasoontorn and S. G. Suo, "Influences onstandards adoption in de facto standardization," Information Technology and Management, vol. 12, no. 4, pp. 1-29, 2011.

[27] H. Lee and S. Oh, "The political economy of standards set-ting by newcomers: China's WAPI and South Korea's WIPI," Telecommunications Policy, vol. 32, no. 9-10, pp. 662-671, 2008.

[28] J.-Y. Choung, I. Ji, and T. Hameed, "International standardization strategies of latecomers: the cases of Korean TPEG, T-DMB, and binary CDMA," World Development, vol. 39, no. 5, pp. 824-838, 2011. 
[29] X. Wu, W. Zhao, and T. Ma, "Improving the impact of green construction management on the quality of highway engineering projects," Sustainability, vol. 11, no. 7, Article ID 1895, 2019.

[30] C. N. Bredillet, "Genesis and role of standards: theoretical foundations and socio-economical model for the construction and use of standards," International Journal of Project Management, vol. 21, no. 6, pp. 463-470, 2003.

[31] D. Saugstrup and A. Henten, " $3 \mathrm{G}$ standards: the battle between WCDMA and CDMA2000," Info, vol. 8, no. 4, pp. 10-20, 2006.

[32] M. Bonnal, "Economic growth and labor standards: evidence from a dynamic panel data model," Review of Development Economics, vol. 14, no. 1, pp. 20-33, 2010.

[33] P. Parrotta, D. Pozzoli, and M. Pytlikova, "Labor diversity and firm productivity," European Economic Review, vol. 66, no. 1, pp. 144-179, 2014.

[34] W. Sanderson, A. Tarasyev, and A. Usova, "Optimal two sector growth models with three factors," Review of Development Economics, vol. 19, no. 1, pp. 85-99, 2015.

[35] U. Lichtenthaler, "Licensing technology to shape standards: examining the influence of the industry context," Technological Forecasting and Social Change, vol. 79, no. 5, pp. 851-861, 2012.

[36] S. Gauch and K. Blind, "Technological convergence and the absorptive capacity of standardisation," Technological Forecasting and Social Change, vol. 91, pp. 236-249, 2015.

[37] H. Jiang, S. Zhao, X. Wang, and Z. Bi, "Applying electromagnetic field theory to study the synergistic relationships between technology standardization and technology development," Systems Research and Behavioral Science, vol. 30, no. 3, pp. 272-286, 2013.

[38] H. Jiang, S. Zhao, K. Yin, Y. Yuan, and Z. Bi, “An analogical induction approach to technology standardization and technology development," Systems Research \& Behavioral Science, vol. 31, no. 3, pp. 366-382, 2014.

[39] J.-H. Paik, M.-K. Kim, and J.-H. Park, "The antecedents and consequences of technology standardizations in Korean IT small and medium-sized enterprises," Information Technology and Management, vol. 18, no. 4, pp. 293-304, 2017.

[40] J. J. Wei, "Research on standardization state evaluation and path selection of the construction enterprise in China," M.A. thesis, Harbin Institute of Technology, Harbin, China, 2015.

[41] W. Yang, H. Y. Wu, and C. P. Yang, "A comprehensive evaluation on competitive power of technology standards based on the technology-market-regulation model," Research and Development Management, vol. 22, no. 1, pp. 18-25, 2010.

[42] T. Elghamrawy and F. Boukamp, "Managing construction information using RFID-based semantic contexts," Automation in Construction, vol. 19, no. 8, pp. 1056-1066, 2010.

[43] X. Du, "Stage division and main task of local standard compilation of engineering construction," Architectural Design Management, vol. 28, no. 8, pp. 38-39, 2011.

[44] Q. F. Jiang, Study on performance evaluation of standardization strategy for construction enterprises, Ph.D. thesis, Wuhan University, Wuhan, China, 2013.

[45] Y. C. Huang, Y. Luo, X. Q. Wang, F. S. Xia, M. Xu, and H. T. Zhang, "Study on modeling work safety standardization operation mechanism and optimization," China Safety Science Journal, vol. 23, no. 4, pp. 159-166, 2013.

[46] H. Zhang, Z. Qiao, and F. Sun, "Contrast analysis of standardization economic contribution rate," in Proceedings of the 19th International Symposium on Advancement of
Construction Management and Real Estate, pp. 1139-1148, Springer, Berlin, Germany, April 2015.

[47] D. M. Zeng and X. Y. Wang, "Modular innovation network tie breadth, technological standardization capability and firms' product innovation," Journal of Xiangtan University (Philosophy and Social Sciences), vol. 43, no. 3, pp. 77-81, 2019.

[48] M. T. Newaz, P. R. Davis, M. Jefferies, and M. Pillay, "Developing a safety climate factor model in construction research and practice: a systematic review identifying future directions for research," Engineering, Construction and Architectural Management, vol. 25, no. 6, pp. 738-757, 2018.

[49] M. T. Newaz, P. Davis, M. Jefferies, and M. Pillay, "Using a psychological contract of safety to predict safety climate on construction sites," Journal of Safety Research, vol. 68, pp. 9-19, 2019.

[50] C. T. Jahren and D. W. Johnston, "Linkages between construction engineering education and research," Journal of Construction Engineering and Management, vol. 137, no. 10, pp. 887-894, 2011.

[51] H. Zhao and N. Li, "Performance evaluation for sustainability of strong smart grid by using stochastic AHP and fuzzy TOPSIS methods," Sustainability, vol. 8, no. 2, pp. 129-150, 2016.

[52] D. Asadi and E. M. Atkins, "Multi-objective weight optimization for trajectory planning of an airplane with structural damage," Journal of Intelligent \& Robotic Systems, vol. 91, no. 3-4, pp. 667-690, 2018.

[53] Y. Wu, J. Wang, S. Ji, Z. Song, and Y. Ke, “Optimal investment selection of industrial and commercial rooftop distributed PV project based on combination weights and cloud-TODIM model from SMEs' perspectives," Journal of Cleaner Production, vol. 234, pp. 534-548, 2019.

[54] T. Luan and Z. Xie, "Work safety standardization grade evaluation model and system development of bauxite mines," Procedia Engineering, vol. 26, pp. 1927-1933, 2011.

[55] Z. Wang and W. Gao, "The study of management information system for coal mine safety quality standardization," Procedia Engineering, vol. 26, pp. 1970-1976, 2011.

[56] Y. Zhang, Research on evaluation theory and method for regional standard of engineering construction, $\mathrm{Ph} . \mathrm{D}$. thesis, Xi' an University of Architecture and Technology, Xi'an, China, 2016.

[57] Y. J. Jia, "Research on the effect of engineering construction standards on construction enterprises," M.A. thesis, Harbin Institute of Technology, Hrabin, China, 2008.

[58] H. Y. Liu, "Research on evaluation of the implementation of engineering construction standard for construction projects," M.A. thesis, Northeast Forestry University, Hrabin, China, 2015.

[59] X. D. Wu, "Research on the evaluation method of construction standardization effect on national economy," M.A. thesis, Beijing Jiaotong University, Beijing, China, 2010.

[60] H. M. Wang and Y. K. Su, "Construction of evaluation index system for standardization ability of construction enterprises," Science Technology and Engineering, vol. 19, no. 36, pp. 270-278, 2019.

[61] J. K. Yates and S. Aniftos, "Developing standards and international standards organizations," Journal of Management in Engineering, vol. 14, no. 4, pp. 57-63, 1998.

[62] L. L. Xie, T. Han, Y. Hu, and Y. Le, "Indicator system of corporate social responsibility for construction contractors in China," Journal of Civil Engineering and Management, vol. 35, no. 6, pp. 36-42, 2018. 
[63] A. H. Zhang and M. H. Huang, "Construction of performance evaluation index system for soft science project," Statistics \& Decision, vol. 35, no. 10, pp. 32-35, 2019.

[64] Y. S. Chen, "Standardization reform and legal improvement based on the U.S. standards regulation perspective," China Standardization, no. 11, pp. 49-55, 2015.

[65] L. J. Guo, Y. Lu, S. Gao, and Y. S. Zhao, "Evaluation model for operation of geological prospecting units safety standardization based on blind number and CMM theory," Science Technology and Engineering, vol. 14, no. 17, pp. 311-316, 2014.

[66] Y. X. Wei, "Research on management standardization of the construction enterprise," M.A. thesis, Tianjin University, Tianjin, China, 2012

[67] S. H. Dong, "Study on establishment and evaluation of construction standard," M.A. thesis, Northeast Forestry University, Harbin, China, 2010.

[68] Z. Sun, "Research on establishment of construction standard system in China," M.A. thesis, Harbin Institute of Technology, Harbin, China, 2010.

[69] S. S. Wang, J. L. Wu, and H. Q. Wang, "Research on the structural dimensions and evaluation index of industrial technology standardization capability," Science of Science and Management of S \& T, vol. 34, no. 6, pp. 112-118, 2013.

[70] S. L. Li, J. L. Zhang, and S. Liu, "Measuring social security policy implementation effect based on multidimensional and hierarchical scale," Management Review, vol. 27, no. 3, pp. 24-38, 2015.

[71] L. Y. Li, Y. J. Guo, and S. T. Huang, "A research on the evaluation of provincial science and technology based on modifiable feature," Science Research Management, vol. 39, no. S1, pp. 122-129, 2018.

[72] N. Chen, S. L. Wang, D. S. Fu, and J. Zhao, "Basic experimental evaluation on safety behavior competence of construction workers based on FAHP," Journal of Civil Engineering and Management, vol. 36, no. 1, pp. 28-33, 2019.

[73] Y. Lin, C. Lin, and X. Qiu, "Fuzzy comprehensive evaluation method of masonry structure safety based on grey clustering theory," Mathematical Problems in Engineering, vol. 2018, no. 5, 15 pages, Article ID 8710192, 2018.

[74] B. Jiang and M. B. Xu, "Study on innovation ability evaluation of small and micro enterprises based on triangular fuzzy number and fuzzy closeness degree," Chinese Journal of Management Science, vol. 24, no. S1, pp. 685-692, 2016.

[75] Z. Jin and J. Gambatese, "Exploring the potential of technological innovations for temporary structures: a survey study," Journal of Construction Engineering and ManagementASCE, vol. 146, no. 6, Article ID 04020049, 2020.

[76] Q. Abueisheh, P. Manu, A. M. Mahamadu, and C. Cheung, "Design for safety implementation among design professionals in construction: the context of Palestine," Safety Science, vol. 128, Article ID 104742, 2020.

[77] P. T. Yi, W. W. Li, and Y. J. Guo, "Structure stability analysis of linear dimensionless methods," Journal of Systems \& Management, vol. 23, no. 1, pp. 104-110, 2014.

[78] H. Jiang, H. Xu, S. Zhao, and Y. Chen, "Selection of technology standardization mode for libraries based on game theory," Library Hi Tech, vol. 38, no. 1, pp. 233-250, 2019.

[79] R. Yuan, J. Z. Xiao, N. Milonas, and J. H. Zou, "The role of financial institutions in the corporate governance of listed Chinese companies," British Journal of Management, vol. 20, no. 4, pp. 562-580, 2009. 